\title{
EVIDENCE FOR SYNONYMY BETWEEN TETRANYCHUS URTICAE AND TETRANYCHUS CINNABARINUS (ACARI, PROSTIGMATA, TETRANYCHIDAE): REVIEW AND NEW DATA
}

\author{
Philippe Auger ${ }^{1, *}$, Alain MigeON ${ }^{1}$, Edward A. UeCKermanN ${ }^{2,3}$, Louwrens TiedT $^{3}$ and \\ Maria NAVAJAS ${ }^{1}$
}

(Received 19 April 2013; accepted 02 June 2013; published online 19 December 2013)

${ }^{1}$ Institut National de la Recherche Agronomique, UMR CBGP (INRA / IRD / CIRAD / Montpellier SupAgro), Campus international de Baillarguet, CS 30016, F-34988 Montferrier-sur-Lez cedex, France. ( ${ }^{*}$ Corresponding author) auger@supagro.inra.fr, migeon@supagro.inra.fr, navajas@supagro.inra.fr

2 ARC-Plant Protection Research Institute, Private bag X134, Queenswood, Pretoria, 0121, South Africa. UeckermannE@arc.agric.za

${ }^{3}$ North-West University, Potchefstroom Campus, Laboratory for Electron Microscopy, CRB, Potchefstroom, 2520 South Africa. Louwrens.Tiedt@nwu.ac.za

\begin{abstract}
The species status of Tetranychus cinnabarinus remains uncertain for some acarologists. In the present paper, we propose to examine the taxonomic status of this tetranychid mite through a review of studies that aimed to clarify its taxonomical position. We present and discuss the main results concerning the principal aspects investigated literature published since the description of Boisduval in 1867. These studies concern morphological, biological and molecular data which have been used to separate or to synonymise T. cinnabarinus and Tetranychus urticae. Additional new morphological and biological data are also included. In light of the data presented, the authors conclude that T. cinnabarinus should be considered as a synonym of the polymorphic species T. urticae to which it constitutes the red form.
\end{abstract}

KEYWORDS - synonymy; Tetranychidae; green form; red form; breeding; morphology; molecular data

\section{INTRODUCTION}

In the genus Tetranychus Dufour the taxonomic status of the tetranychid mites known as Tetranychus urticae Koch, 1836 complex [or Tetranychus telarius (L., 1758) sensu Pritchard and Baker, 1955] is a long standing issue among acarologists. In the last catalogue of the spider mite family (Bolland et al., 1998), 44 species names have been synonymised with $T$. urticae and 47 in the Spider Mites Web database (Migeon and Dorkeld, 2006-2013). Among them, the case of the systematic status of Tetranychus cinnabar- inus Boisduval, 1867 has caused a lot of ink to flow. One of the main reasons is that its original description is succinct and mainly based on the colour of the mite: "une belle couleur rouge aurore" meaning a beautiful aurora red colour. Since the second part of the last century, the validity of the taxonomical status of $T$. cinnabarinus has been often questioned. Numerous authors have addressed this complex issue without reaching a consensus on the validity or synonymy of this taxon with T. urticae. In addition to the body colour of the mite, several other criteria have been used either in support of the separation 
TABLE 1: Criteria used to separate and synonymize Tetranychus urticae and Tetranychus cinnabarinus in the literature dealing with the taxonomic status of the red form of T. urticae.

\begin{tabular}{|c|c|c|}
\hline & $\begin{array}{l}\text { Literature supporting the validity of } \\
\text { T. cinnabarinus } \\
\end{array}$ & $\begin{array}{l}\text { Literature supporting the synonymy of } \\
\text { T. cinnabarinus with T. urticae } \\
\end{array}$ \\
\hline $\begin{array}{l}\text { Morphological } \\
\text { criteria }\end{array}$ & $\begin{array}{c}\text { Dorsal integumentary lobe shape }(1,2,3,4,5) \\
\text { Aedeagus shape }(4,6) \text {; Foreleg chaetotaxy }(4,5) \\
\text { Combination of characters }(5) ; \\
\text { Taxonomical monography }(30,31)\end{array}$ & $\begin{array}{l}\text { Dorsal integumentary lobe shape }(24) \text {; } \\
\text { Taxonomical monography }(32,33,34,35)\end{array}$ \\
\hline Biological criteria & $\begin{array}{c}\text { Reproductive isolation }(1,2,6,7,8,9,10,11,12,13,14,15,16,17) ; \\
\text { Ability to enter in diapause }(6,8,10,12,18,19,20) ; \\
\text { Host plant adaptation }(8,10,21) ; \\
\text { Physiological traits }(4,22,23) ; \text { Population genetics }(23)\end{array}$ & $\begin{array}{l}\text { Reproductive isolation defective }(22,25,26,27,36) \\
\text { Ability to enter in diapause }(22,25,28,29)\end{array}$ \\
\hline
\end{tabular}

Literature cited

(1) Boudreaux (1956), (2) Monroe (1963), (3) Brandenburg and Kennedy (1981), (4) Kuang and Cheng (1990), (5) Zhang and Jacobson (2000), (6) Dillon (1958), (7) Taylor and Smith (1956), (8) Hussey and Parr (1958), (9) Parr and Hussey (1960), (10) Van de Bund and Helle (1960), (11) Boudreaux (1963), (12) Boudreaux and Dosse (1963a), (13) Dosse and Boudreaux (1963), (14) Dosse and Nuber (1963), (15) Saba (1975), (16) Smith (1975), (17) Jordaan (1977), (18) Boudreaux (1958a), (19) Helle and Van de Bund (1962), (20) Hazan et al. (1971), (21) Dosse (1952), (22) Gotoh and Tokioka (1996), (23) Goka et al. (1996), (24) Mollet and Sevacherian (1984), (25) Dupont (1979), (26) Boer (1982), (27) Gotoh et al. (1993), (28) Helle and Overmeer (1973), (29) Vaz Nunes (1986), (30) Zhang (2003), (31) Meyer (1974), (32) Meyer (1987), (33) Baker and Tuttle (1994), (34) Bolland et al. (1998), (35) Ehara (1999), (36) Attwa et al. (2011).

or on the contrary to synonymize T. urticae and $T$. cinnabarinus. Table 1 summarizes the main relevant literature on this topic.

More recently, molecular approaches have been added to morphological criteria to address the controversy on the taxonomical status of T. cinnabarinus. Unexpectedly, molecular analyses have partly revived this controversy. While most of the molecular studies conclude that the two forms are synonymous (Navajas, 1998; Hinomoto et al., 2001; de Mendonça et al., 2011; Sun et al., 2012) or do not achieve to separate them (Xie et al., 2006b; Xie et al., 2008), a recent work wrapped up to the validity of this species (Li et al., 2009). While molecular studies have proved to be of high value for systematics studies of many groups including the Acari, DNA sequences information needs to be manipulated with much precaution. In particular, the reliability of the DNA data available in public sequence DNA databases, i.e. GenBank, might lack proper taxonomy. In the case of difficult taxonomic issues as $T$. cinnabarinus, wrongly attributed sequences to species is responsible for erroneous inferences concerning the taxonomic position of this species (Hinomoto et al., 2007; Ros and Breeuwer, 2007; de Mendonça et al., 2011). Thus, rather than solving the taxonomic position of T. cinnabarinus, molecular data have increased the confusion regarding validity of this taxon.

The aim of the present paper is to review the literature used to separate or synonymize T. urticae and $T$. cinnabarinus. The criteria examined include: colour of mites, morphological features like the dorsal integumentary lobe pattern, aedeagus shape and female leg I chaetotaxy; biology concerning breeding, diapause and host plant adaptation and molecular approach with phylogenetical relationships between the two taxa. The ability to develop resistance to pesticides in the two colour forms was not investigated. In our opinion, data do not allow to know if the resistance development in a colour form is more due to its innate capacity to develop resistance than to variable selection pressures as a result of differences in amounts and types of pesticides applied.

In addition, for two of the criteria above mentioned we performed biological experiments (crosses) and morphological measurements (shape of the aedeagus) on five red and green populations. By analysing together published information and new data, this paper sheds new light on the taxonomical status of T. cinnabarinus and allows to conclude on its synonymy with T. urticae. 


\section{MATERIALS AND METHODS}

\section{SEM photographs}

Mites were fixed in $70 \%$ ethanol for $24 \mathrm{~h}$ and dehydrated in an ethanol series of $80 \%, 90 \%$, and 2 X $100 \%$ for 15 min each. The dehydrated samples were critical point dried using liquid carbon dioxide as transitional fluid. After drying the mites were mounted on SEM stubs with double sided carbon tape and coated with a layer of $20 \mathrm{~nm}$ gold/palladium using a sputter coater. The mites were viewed in a FEI Quanta 250 ESEM operating under high vacuum mode at $5-10 \mathrm{kV}$.

\section{Shape of the aedeagus study}

Dimensions of aedeagi of males belonging to three strains of green form (GF) (collected in France, Canada and Scotland) and of two strains of red form (RF) (collected in Spain and in Southern France) (Table 2) have been compared.

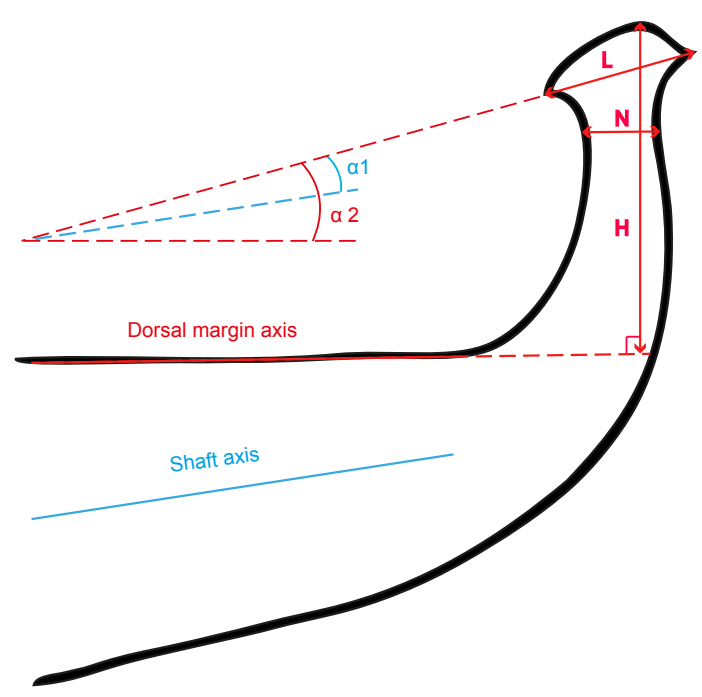

FIGURE 1: Parameters measured for the comparison of the aedeagus of the two colour forms of Tetranychus urticae: length of the knob $(\mathrm{L})$, width of the neck $(\mathrm{N})$, high of the hook $(\mathrm{H})$, angle between the axis of the knob and the axis of the shaft $\left(\alpha_{1}\right)$ and angle between the axis of the knob and the axis of the dorsal margin of the shaft $\left(\alpha_{2}\right)$.

Approximately 15 males per strain ( 13 to 16 , depending on the character measured), mounted in Hoyer medium (kept in alcohol and cleared in lactic acid for one day before mounting), were examined using a Leica DM LB 2 phase contrast microscope (10 x 25 HC Plan, Fluotar 100) at a magnification of 2000. Measured parameters are shown in Figure 1. Measurements were obtained using the imaging software Perfect Image ${ }^{\circledR}$ (Clara Vision) coupled with Progres ${ }^{\circledR}$ Capture Pro 2.6 software for image acquisition. Data were analysed with an ANOVA completed by the Newman-Keuls test $(\alpha=5 \%)$.

\section{Breeding experiments}

To assess the reproductive compatibility between the two colour forms, crosses and reciprocal crosses with two populations of the GF (from Canada and Scotland) and two populations of the RF [collected in Spain and in Southern France, populations studied in the previous section (Table 2)] were performed. Thirty deutonymphs of each stock cultures were isolated on bean leaves (placed on wet cotton at $22{ }^{\circ} \mathrm{C}$ and 16L:8D) with an equal number of mature males from the required population. All the populations were tested for the endosymbionts Wolbachia presence (Perrot-Minnot et al., 2002). No Wolbachia were detected. Females were allowed to laid eggs and they were removed (with males) when the offspring of the cross reached the deutonymph stage. The number of emerging F1 females and males were recorded. Newly emerged F1 females were allowed to mate with their brothers, transferred to new leaves and their adult progeny was also scored. In some cases, when available, the F2 females and those of the next generations were allowed to mate with their brothers and cousins and so on.

TABLE 2: Collection locations and host plants of green from (GF) and red form (RF) populations of Tetranychus urticae used for aedeagus measurements and breeding experiments.

\begin{tabular}{llll}
\hline $\begin{array}{c}\text { T. urticae } \\
\text { populations }\end{array}$ & \multicolumn{1}{c}{ Locality } & \multicolumn{1}{c}{$\begin{array}{c}\text { Geographical } \\
\text { coordinates }\end{array}$} & \multicolumn{1}{c}{ Host plant } \\
\hline GF France & 30 years rearing & - & Phaseolus vulgaris \\
GF Canada & London (ON) & $43.00^{\circ} \mathrm{N} 81.28^{\circ} \mathrm{W}$ & Phaseolus vulgaris \\
GF Scotland & Longforgan (P \& K) & $56.42^{\circ} \mathrm{N} 3.12^{\circ} \mathrm{W}$ & Fragaria x ananasa \\
RF Spain & Banyoles (GI) & $42.12^{\circ} \mathrm{N} 2.77^{\circ} \mathrm{E}$ & Solanum lycopersicum \\
RF France & Alenya (66) & $42.64^{\circ} \mathrm{N} 2.97^{\circ} \mathrm{E}$ & Solanum lycopersicum \\
\hline
\end{tabular}



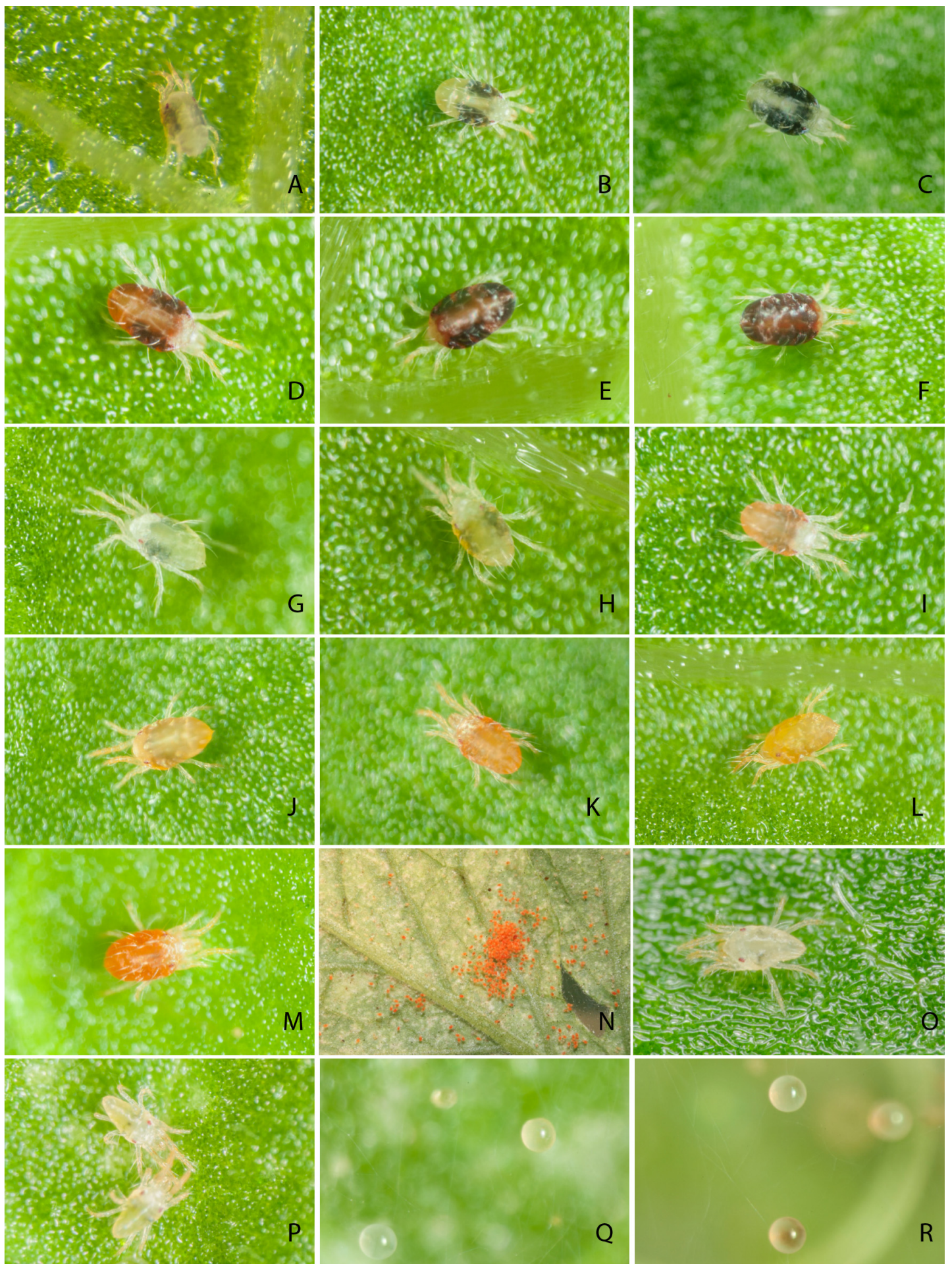

FiguRE 2: A, B, C - Colours variations in active green form (GF) females of Tetranychus urticae: A - yellowish green, B - yellowish; C - old dark female; D, E, F - Colours variations in active red form (RF) females of T. urticae: D - carmine red, E - dark red, F - old dark female; Young females of GF (G) and RF (H, I); Starved female of T. urticae showing reduced side spots: J - orange like GF, K brightly orange RF; Hivernating females of T. urticae: L - GF bright pale orange, M - RF brightly orange, N - RF brightly orange red; Male of the GF of T. urticae $(\mathrm{O})$ and males of the RF (P); Colour variations in eggs: $\mathrm{Q}$ - eggs of GF, $\mathrm{R}$ - eggs of RF. 


\section{RESULTS ON REVIEW AND NEW DATA}

For each criteria investigated, data found in the literature are presented first followed by new data when available.

\section{Morphological characters}

\section{Colour of mites}

While the colour of mites is basically physiologically determined, it has been used as morphological trait to separate RF and GF, and it is included in this paragraph. This parameter is the only criterion available to distinguish between T. urticae and T. cinnabarinus when referring to the original description of T. cinnabarinus by Boisduval (1867). Several aspects of the colour have been investigated in relation with the RF and GF.

\section{Adults' body colour}

Depending on the author, the two colour forms of T. urticae may vary in name (Table 3). According to Boudreaux (1956), who reinstated T. cinnabarinus, the colour of the two forms are the following: active females of the green form (GF) are yellowish or green to dark green, whereas the red form (RF) is carmine red in colour (=carmine spider mite), the carmine colour appearing only in apart of the adult stage (Ewing, 1914; Van de Bund and Helle, 1960; Boudreaux and Dosse, 1963a), a few days after moulting, colour darkens with advancing age (Van de Bund and Helle, 1960) and old females being uniformly dark ruby (Dosse, 1952) (Figure 2 A-F). In addition to the overall body colour of the mite, Boudreaux (1956) also separated the two colour forms by the shape and the number of dark food spots on the dorsal part of the female hysterosoma. Their characteristics are given in Figure 2 A, D, Figure 3 and in Table 3. Blauvelt (1945) has shown that the outer surface of the ventriculus (mid-gut) is indented at several intervals by dorsoventral muscles that divide the ventriculus in several broad caeca. The amount and the place where food accumulates into these caeca are responsible for the colour, the shape and the number of dark food spots on the body of the mite. Other female colour data that depend on their feeding activity and those of males, juveniles and eggs of the two forms are also reported in Table 3 and in Figures 2 G-R.

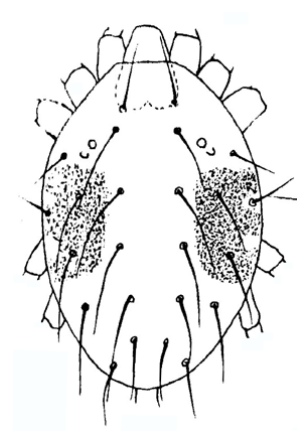

A

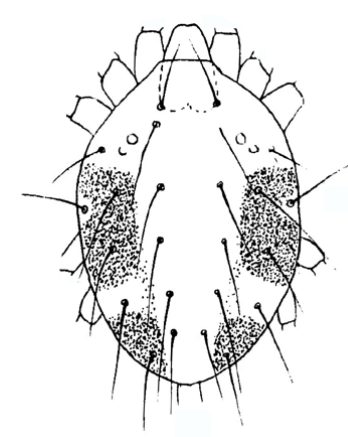

B
FIGURE 3: A - Drawing of a GF female of Tetranychus urticae with one pair of trifid feeding spots; B - Drawing of a RF female of T. urticae with the typical pair of trifid feeding spots and the caudal pair of spots (original drawings from $\mathrm{H}$. Bruce Boudreaux - 1956 - Ann. Entomol. Soc. of Ame.,, 49: 4348)

\section{Physiological basis of mite colour}

Colouration in the two forms of T. urticae is mainly caused by internal pigments because cuticle is not coloured (Metcalf and Newell, 1962; Veerman, 1974; Geest, 1985). Metcalf and Newell (1962) were the first to compare the nature of the pigments of GF and RF concluding that tetranychid mite pigments are derived from chlorophyll and carotenoids present in the mite diet. A detailed pigment analysis of the two colour forms has been done by Veerman (1974). He found that the same carotenoids are present in the two forms but with differences in the number of keto-carotenoids which were $5 \mathrm{vs}$. 9 in the GF and the RF respectively. However the author later questioned these results attributing the differences to the technical protocol used (Veerman, 1974). A pigment analysis of the RF and of another green/yellow tetranychid, Tetranychus pacificus McGregor, 1919, revealed that despite an obvious difference in their body colour these two mites had the same range of carotenoids which were quantitatively very close (Veerman, 1972). Moreover, in deeply orange coloured diapausing females of the GF, the RF and of T. pacificus, the number of ketocarotenoids is identical in the three mites and two- 
TABLE 3: Comparison of several morphological and biological features in the two colour forms of Tetranychus urticae.

\begin{tabular}{|c|c|c|c|}
\hline & Green form & Red form & Figures \\
\hline $\begin{array}{l}\text { Active Female body } \\
\text { colour }\end{array}$ & $\begin{array}{l}\text { brownish or nearly black (1); yellowish-green }(5,9,25) \text {; amber varying to } \\
\text { dark green (5); yellowish or green to dark green }(7)\end{array}$ & $\begin{array}{l}\text { yellowish-red (2); orange red (3); brownish-red/reddish-brown }(4,9, \\
\text { 13); dark brownish red (5); dark red }(6,25) \text {; carmine red }(7) \text {; deep red } \\
\text { (8) }\end{array}$ & (Figs. $2 \mathrm{~A}-\mathrm{F}$ ) \\
\hline $\begin{array}{l}\text { Young female body } \\
\text { colour }\end{array}$ & amber coloured (3) & amber coloured (3); pale-amber in colour with orange tint (5) & (Fig. 2 G-I) \\
\hline $\begin{array}{l}\text { Starved female body } \\
\text { colour }\end{array}$ & amber tint with a frequent orange-like glow (5) to brick-red colour (4) & brightly orange in colour (5); brick-red pigment (4) & (Fig. $2 \mathrm{~J}, \mathrm{~K}$ ) \\
\hline $\begin{array}{l}\text { Hivernating female } \\
\text { body colour }\end{array}$ & $\begin{array}{l}\text { bright pale orange (e.g. } 1,5,14,15) \text {; orange yellow (16); deep orange } \\
\text { (20); bright orange (24); orange red }(13,17,23)\end{array}$ & $\begin{array}{l}\text { no differences with the GF when exposed to low temperatures }(1,5 \text {, } \\
13,14) \text {; }\end{array}$ & (Fig. $2 \mathrm{~L}-\mathrm{N}$ ) \\
\hline $\begin{array}{l}\text { Feeding dark spots in } \\
\text { active females }\end{array}$ & $\begin{array}{l}\text { a pair of large black spots often trifid }(10,11) \text { or divided into } 2 \text { or } 3 \\
\text { smaller ones (5); a second pair may also be present }(3,12)\end{array}$ & $\begin{array}{l}2 \text { pairs, the anteriors larger and bifid (11) the second pair in the } \\
\text { caudal area }(2,11) \text {; second pair of spots sometimes lacking }(7)\end{array}$ & (Figs. 2 B, E) \\
\hline $\begin{array}{l}\text { Feeding dark spots in } \\
\text { young females }\end{array}$ & \multicolumn{2}{|c|}{ both bear pale-brown side-spots (5) enlarging with age (7) } & (Fig. 2 G-I) \\
\hline $\begin{array}{l}\text { Feeding dark spots in } \\
\text { starved/diapausing } \\
\text { females }\end{array}$ & \multicolumn{2}{|c|}{$\begin{array}{l}\text { side spots reduced and often subdivided with starvation (5); lacking in diapausing female or when exposed to low temperatures } \\
\qquad \text { (e.g. } 1,5,13,14,15,20)\end{array}$} & (Fig. $2 \mathrm{~J}-\mathrm{M}$ ) \\
\hline \multirow[t]{2}{*}{ Male body colour } & \multicolumn{2}{|c|}{$\begin{array}{l}\text { males of the two forms are indistinguishable by body's colour }(4,18) \text {; colour may vary from yellowish to pale green }(4,8,18) \text {, } \\
\text { from from light yellow to rust-coloured }(19) \text { to yellowish reddish }(2)\end{array}$} & (Fig. $2 \mathrm{O}, \mathrm{P}$ ) \\
\hline & $\begin{array}{l}\text { pale yellowish green to light amber with sometimes a slight orange-like } \\
\text { tint (5) }\end{array}$ & amber to bright orange-like red with fine dark pigmental spots (5) & \\
\hline Juveniles body colour & \multicolumn{2}{|c|}{$\begin{array}{l}\text { similar in colour, green (7); Pale amber larvae become green coloured when feeding starts, nymphs are yellowish-green in colour }(8,9) \text {; flesh } \\
\text { coloured (21); never orange/red in colour (22) }\end{array}$} & \\
\hline & teleiochrysalis green (21) & $\begin{array}{l}\text { teleiochrysalis pale-brownish-orange (21); nymphs on carnation } \\
\text { (Dianthus caryophyllus L.) orange-like green coloured (5) }\end{array}$ & \\
\hline Eggs colour & $\begin{array}{l}\text { clear white, translucent and shining }(16,3,5) \text { to pale creamy, become } \\
\text { yellowish as they develop }(16,19,20) \text {; yellowish-orange before hatching } \\
\text { (20); never reddish }(11)\end{array}$ & $\begin{array}{l}\text { amber with pink-reddish tint darkening with development (5), pale } \\
\text { to rosy-amber or slightly smoky (3), straw coloured + reddish tinge } \\
\text { as hatching time approaches (21), brownish (4), always with a trace } \\
\text { of red (11), colour more intense when laid by unmated females (11 } \\
\text { some eggs may be clear (12) }\end{array}$ & (Fig. $2 \mathrm{Q}, \mathrm{R}$ ) \\
\hline
\end{tabular}

(1) Pritchard and Baker (1952), (2) Dosse (1952), (3) Dillon (1958), (4) Hussey and Parr (1958), (5) Van de Bund and Helle (1960), (6) Boudreaux (1963), (7) Boudreaux and Dosse (1963a), (8) Veerman (1970), (9) Kuang and Cheng (1990), (10) Pritchard and Baker (1955), (11) Boudreaux (1956), (12) Boudreaux and Dosse (1963b), (13) Dosse (1966), (14) Dosse and Musa (1967), (15) Veerman (1977), (16) Gasser (1951), (17) Parr and Hussey (1966), (18) Parr and Hussey (1960), (19) Hatzinikolis (1970), (20) Veerman (1974), (21) Davis (1961), (22) Ewing (1914), (23) Gotoh (1986), (24) Goka and Takafuji (1990), (25) Gotoh and Tokioka (1996).

fold higher than in active females. Thus, variation in colour between species and between active and diapausing females would be due to variation in keto-carotenoid quantities rather than to differences in their composition. A difference in the expression level of some genes implicated in the carotenoids biosynthesis would be responsible for these variations (Altincicek et al., 2012).

\section{Genetic determinism of mite's colour}

Several authors reported that reciprocal crosses between GF and RF produced hybrids of different nuances of red colour: F1 active females can be pale pinkish red (Boudreaux, 1956), carmine (Keh, 1952; Dillon, 1958; Dosse, 1963), orange-red (Hussey and Parr, 1958; Monroe, 1963), reddish, bright red to dark red (Sugasawa et al., 2002), but rarely carmine red as in females of the RF (Jordaan, 1977) (Figure 4 A, B). The obtained F1 females were never green, suggesting that red is a dominant trait (Keh, 1952;
Taylor and Smith, 1956; Hussey and Parr, 1958; Dosse, 1963; Dosse and Boudreaux, 1963; Monroe, 1963; Jordaan, 1977).

Fertile hybrid females produced in the successive generations may vary from yellow to red (Jordaan, 1977). F2 females can be green, brownish red, orange red (Hussey and Parr, 1958; Monroe, 1963) or dark red, carmine, pink to yellowish (Monroe, 1963). Another type of F2 females called "intermediate" are reddish brown turning green with a faint red tinge with age (Hussey and Parr, 1958) or yellow becoming pinkish after a few days, orange turning green, yellowish turning dark red (Monroe, 1963) and green turning reddish (Keh, 1952; Monroe, 1963). Because of the various patterns of F2 female body colours, Hussey and Parr (1958) concluded that the redness colour cannot be explained by a single red gene dominant over green. They hypothesised that mite colour would be under the 

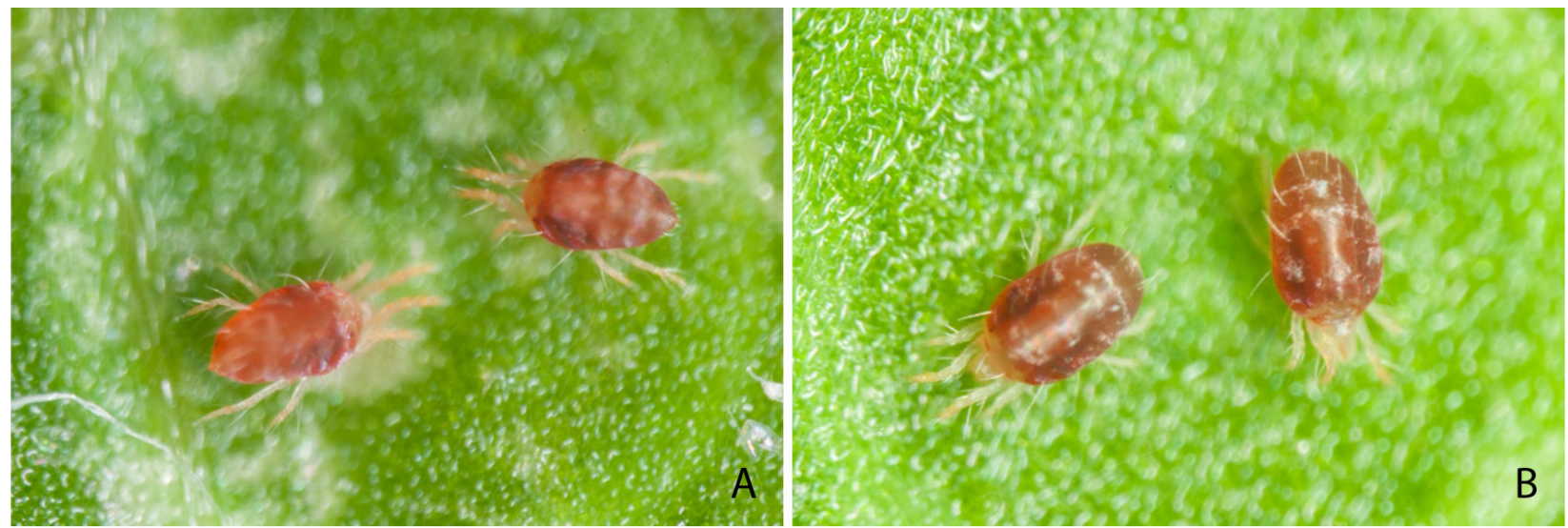

FIGURE 4: A - Typical red hybrid F1 females of Tetranychus urticae obtained when crossing GF and RF ; B - rare red with pinkish glow F1 females.

influence of two pairs of non-allelic genes, which was however regarded as an oversimplification of the situation (Monroe, 1963).

In addition to the whole body colour of the mite, the number of dark food spots and the colour of eggs can also be a mark of hybridization. F1 females might lack dark spots and a pair of atypical supplementary caudal dark spot is often present in F2 and F3 green females (Keh, 1952; Taylor and Smith, 1956) (Figure 5).

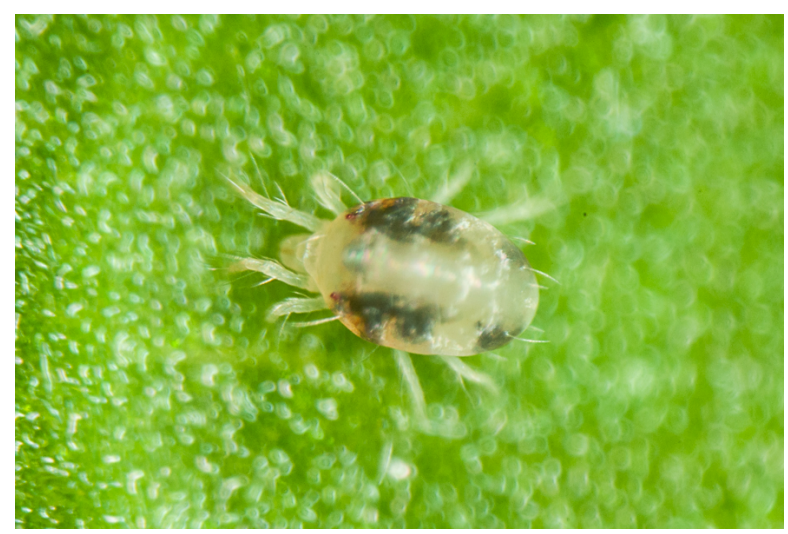

FIGURE 5: Additional caudal dark feeding spots present in a F3 hybrid female having a body colour close to that of the GF of Tetranychus urticae.

The eggs laid by hybrid females and their offspring are variously pigmented (Hussey and Parr, 1958; Monroe, 1963), their colour being frequently linked to the body colour of the female (Monroe, 1963).

\section{Mite colour for species diagnostics}

A few years after the publication of Boisduval (1867) proposing the body colour to distinguish the GF (T. cinnabarinus) from other tetranychid species, Murray (1877) and Harvey (1892) considered that colour was not a reliable criterion to separate mites of the T. urticae species-group. Several authors report that the colouration of individuals may vary with the age of mites (Ewing, 1914; Monroe, 1963), with the feeding activity (Ewing, 1914; Pritchard and Baker, 1952) and with host plant (Gasser, 1951; Pritchard and Baker, 1952; Van de Bund and Helle, 1960). Some additional support of the inadequacy of colour to separate the two taxa is provided by colour variations found in the female progeny of a single female (Figure 6) (Ewing, 1914). This author concluded that large variations in the body colour among individuals of species belonging to the genus Tetranychus were partly responsible for numerous species confusion and that $T$. cinnabarinus would be probably a synonym of T. urticae. This opinion was shared by Dupont (1979) who concluded that colour variations alone are not sufficient for describing a new species because the carotenoid metabolism in the two forms of T. urticae are very similar (Veerman, 1970; 1972; 1974). As body colour is poorly correlated with other morphological characters considered to be far essential 
Auger P. et al.

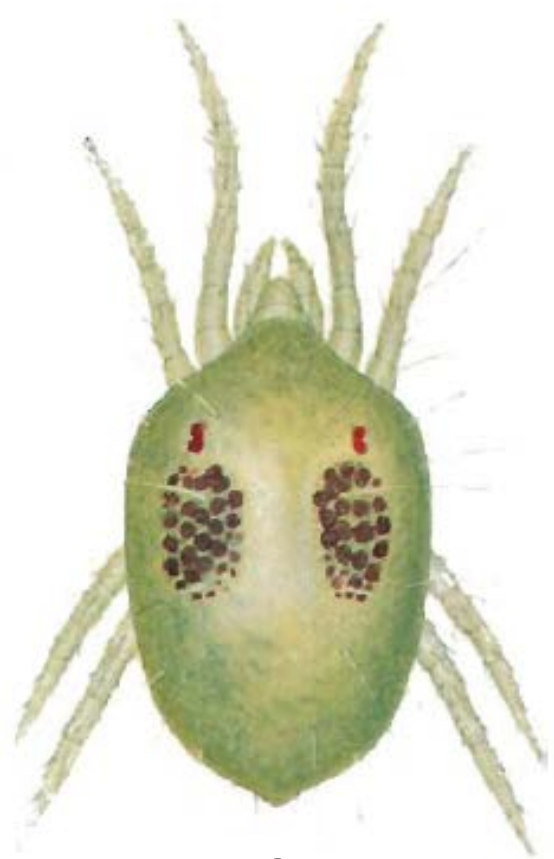

A

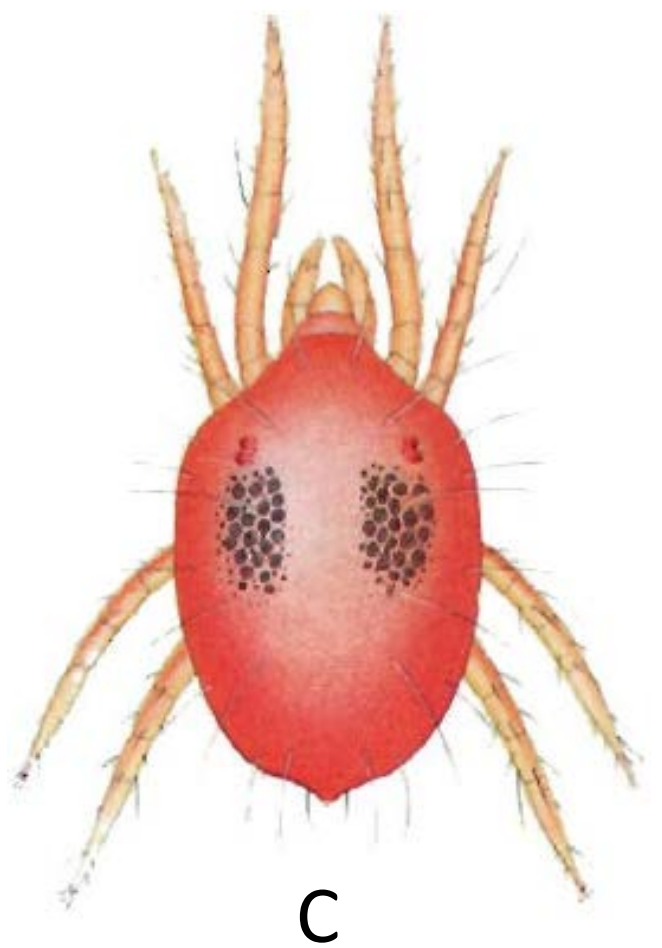

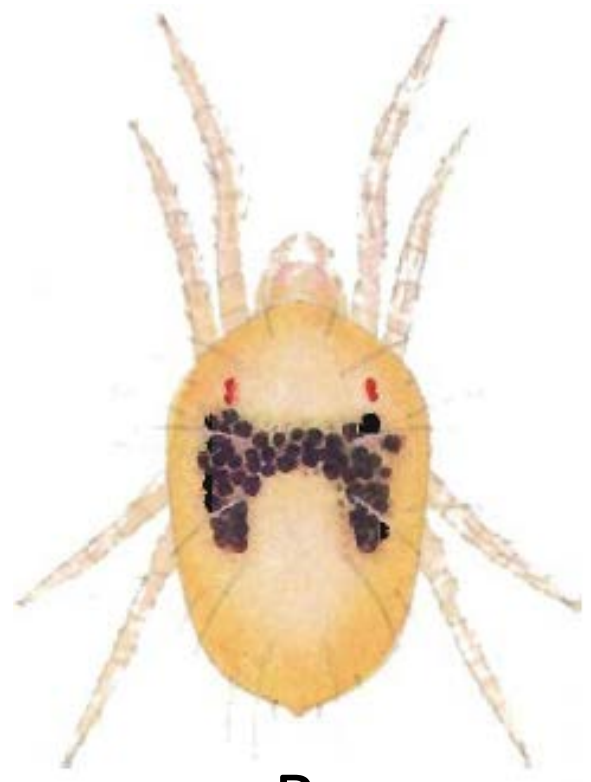

B

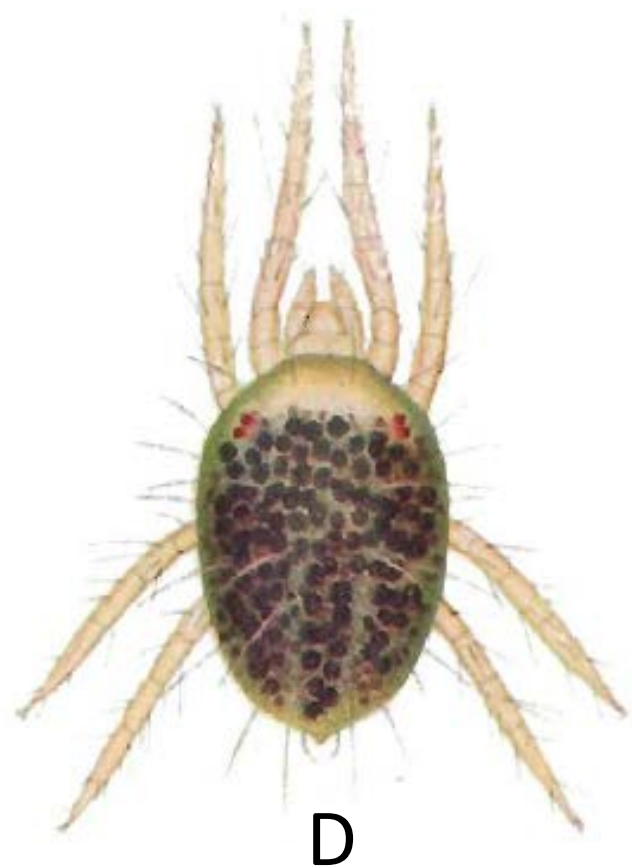

FIGURE 6: Colour variations found among the first and second generation descendants of a single female of T. telarius L. (= red form of Tetranychus urticae). A - active feeding female; B - female after a fasting of two days; C - reddish orange female; D - a black form following vigourous feeding (original drawings from Ewing H. E. - 1914 - Oregon Agricultural College Experimental Station Bulletin, 121: 1-95, permission to reprint these illustrations granted by Oregon State University and the Oregon Agricultural Experiment Station, 2011). 

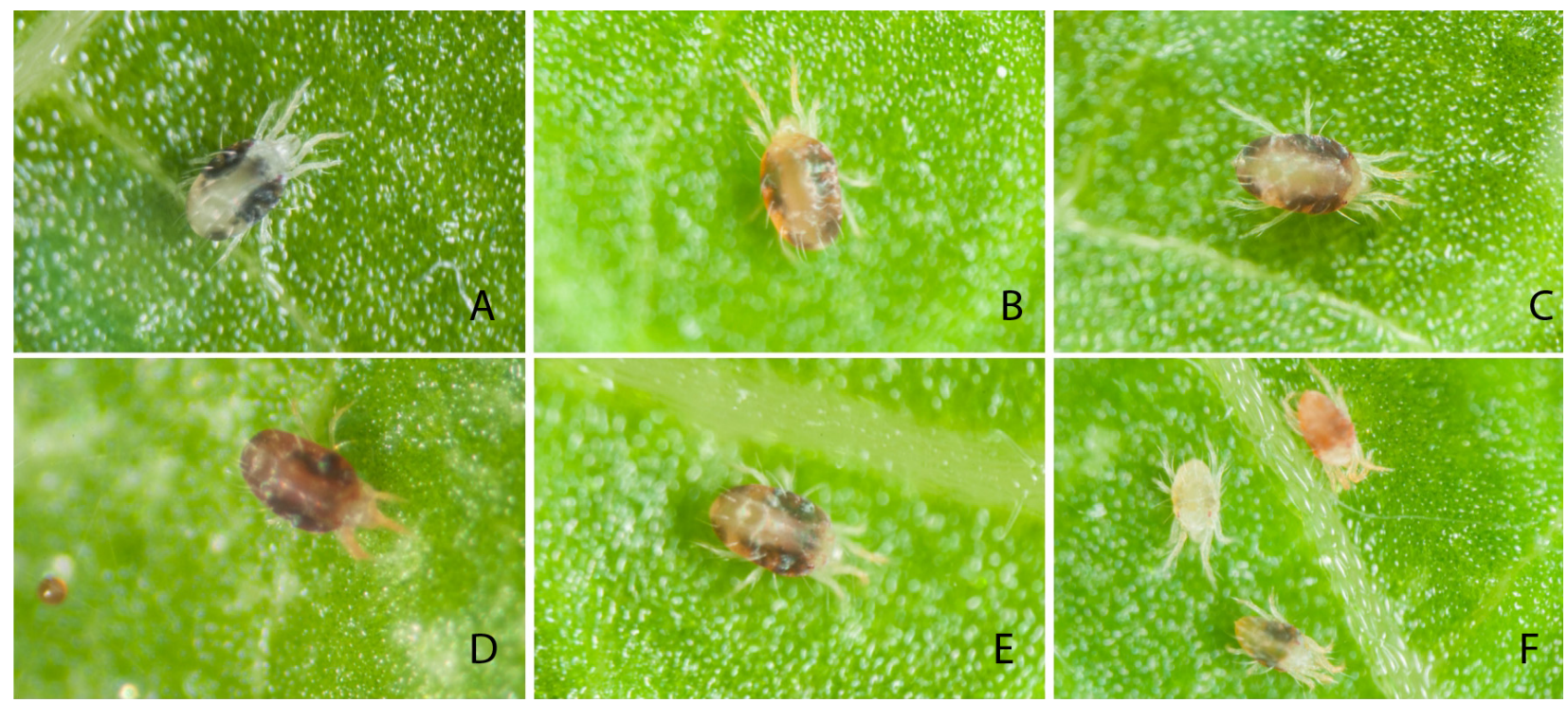

FIgURE 7: Colour variations in hybrid F2 and F3 females of Tetranychus urticae. A - yellowish-green female; B - pale orange female; C yellowish female with pinkish tint; D - brownish red, E - pale pinkish, F-yellowish, orange and bronze coloured females.

for species separation, Zhang and Jacobson (2000) estimated that this trait was not a reliable character to distinguish between the two forms of T. urticae (see "Leg chaetotaxy" and "Other morphological characters" sections below).

Conversely, (Boudreaux, 1956; Boudreaux and Dosse, 1963a) reported that body colour is a reliable trait when used alone or when considered with morphological ones (Boudreaux and Dosse, 1963a). Saba (1975) went further in considering that colour was important data for certain tetranychid mite identifications.

New data

Hybrids' colour. A sample of body colours from F2F3 hybrid females obtained by our crossings (see "Breeding" section for results) is given in Figure 7 and several "intermediate" F8 hybrid females are figured in Figure 8. The additional posterior pair of maculae occurring in the RF but not in the GF (Dosse, 1952; Boudreaux, 1956) has been considered as an additional criterion to separate the two colour forms. However we have observed these maculae on individuals from several populations of the GF and not only in older females as reported by Boudreaux and Dosse (1963b) (Figure 9). Conversely, like Boudreaux and Dosse (1963a) we also found many specimens of the red form lacking these caudal black spots. Thus, this trait is not distinctive of the two colour forms.

Actually most of the tetranychid mite taxonomists consider that $T$. cinnabarinus is a synonym of T. urticae and body's colour is not given as a character to distinguish between these two species (e.g. Meyer, 1987; Baker and Tuttle, 1994; Bolland et al., 1998; Ehara, 1999). In their opinion, T. urticae presents two colour forms, green and red. We will see in the "Breeding" section, that colour cannot be considered as a specific marker.

\section{Lobes on dorsal striation}

\section{Lobe shape and density}

Lobes are small structures of various shapes present on the upper edge of integumentary folds of the body of mites (Figure $10 \mathrm{~A}$ ). On adult GF summer females, the dorsal striation bears semioblong lobes (Boudreaux, 1956), some of them wide or rather oblong, rounded, sometimes narrower and occasionally triangular (Boudreaux and Dosse, 1963b; Monroe, 1963; Carbonnelle and Hance, 2004) but never apically pointed (Brandenburg and Kennedy, 1981) (Figure 10 B, C and D). On RF adults, lobes are semi-circular or triangularly 

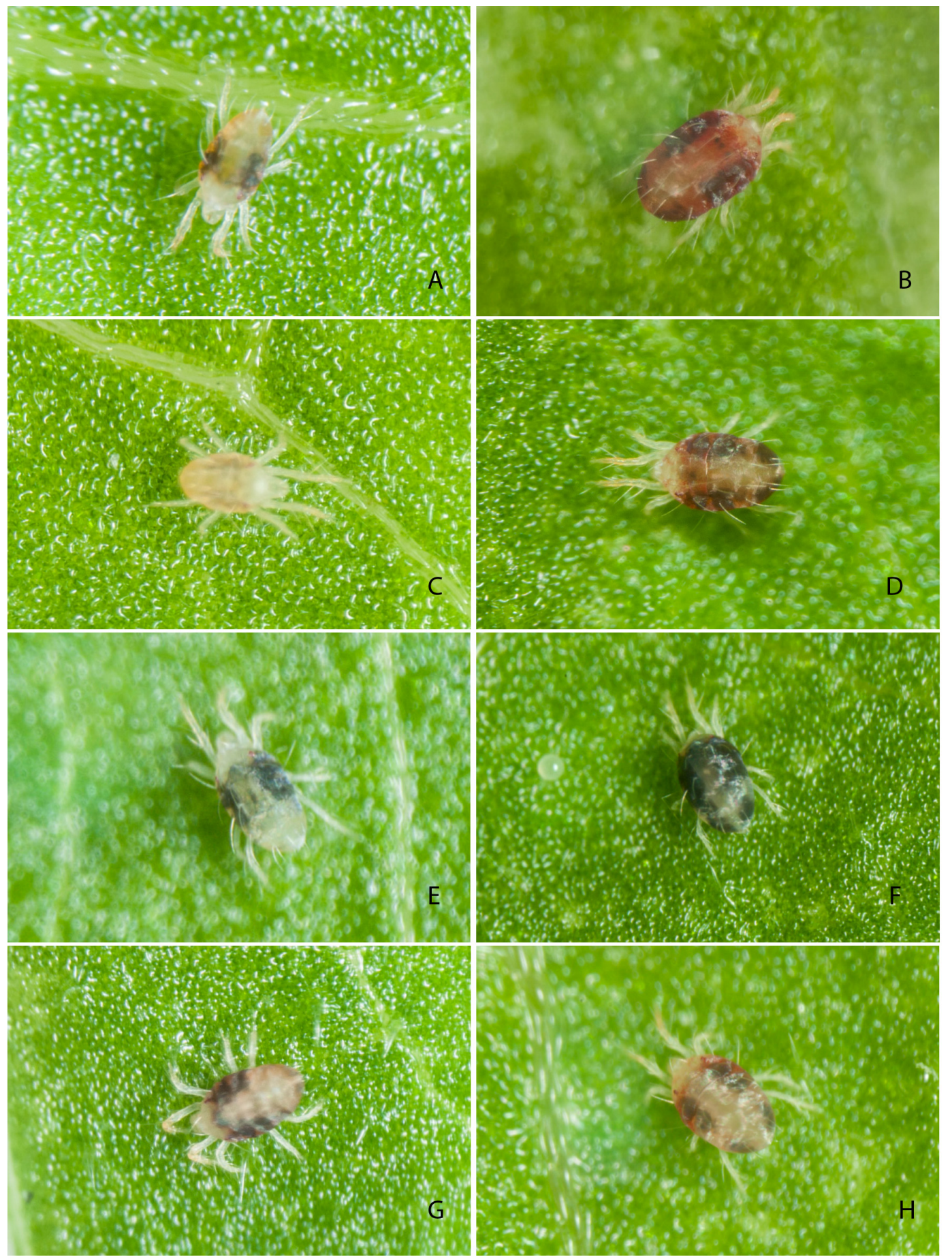

FIGURE 8: Examples of colour changing in hybrid F8 females of Tetranychus urticae: yellowish female (A) that turned pink-red (B); pale pinkish female (C) that turned pink-red (D); yellowish green female (E) that turned dark-green (F); amber female (G) that turned pink-red $(\mathrm{H})$ 
rounded (Boudreaux, 1956), generally more separated at their base, narrow and relatively pointed (Boudreaux and Dosse, 1963b; Monroe, 1963; Carbonnelle and Hance, 2004) (Figure 11 A, B and C).

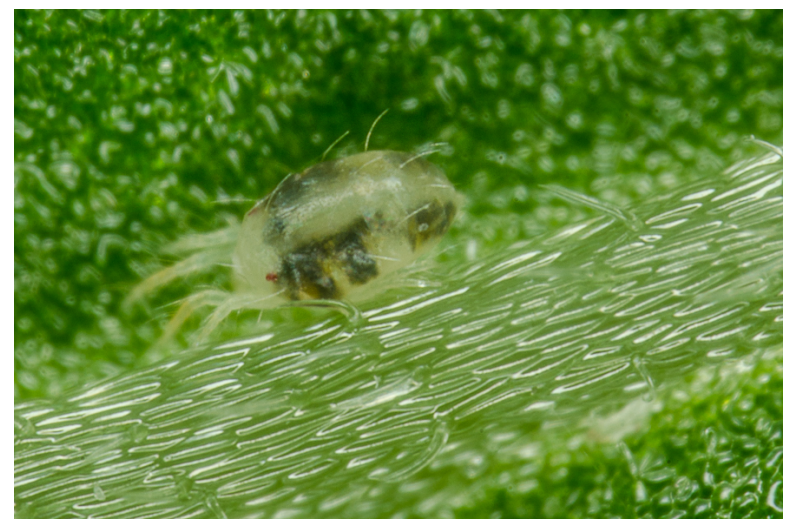

FIGURE 9: GF females of Tetranychus urticae with an additional pair of spots in the caudal area.

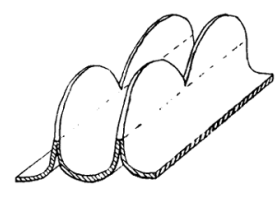

A

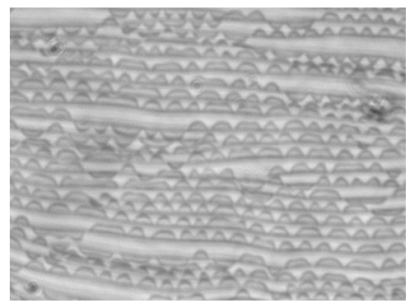

C

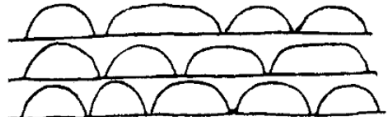

B

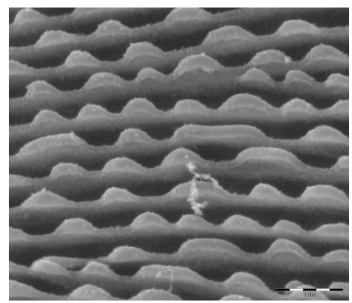

$\mathrm{D}$
FIGURE 10: Cuticular lobes on the dorsal striation of Tetranychus species. A - general aspect and location of lobes on the dorsal integumentary folds; B - cuticular lobes in GF females $T$. urticae (original drawings from $\mathrm{H}$. Bruce Boudreaux - 1956 - Ann. Entomol. Soc. Am., 49: 43-48); C - aspect of GF females of T. urticae lobes using phase-constrast microscope; D - aspect of GF females of T. urticae lobes using SEM.

They are smaller and more triangular than in the GF. However, sometimes broad rounded lobes can be found mixed with other type of lobes (Monroe, 1963; Dosse and Langenscheidt, 1964; Hatzinikolis, 1970; Meyer, 1974; Brandenburg and Kennedy, 1981).

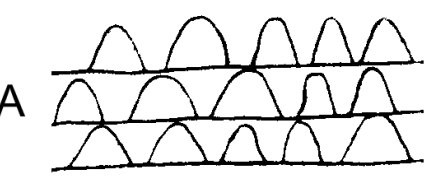

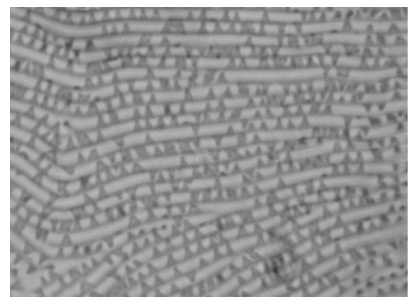

B

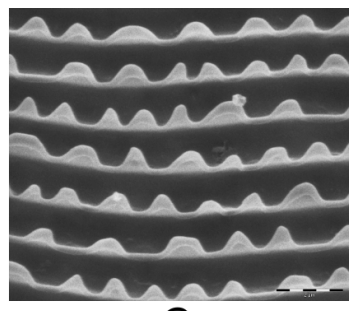

C
FIGURE 11: Cuticular lobes on the dorsal striation of RF females of Tetranychus urticae. A - original drawing by $\mathrm{H}$. Bruce Boudreaux - 1956 - Ann. Entomol. Soc. Am. 1956, 49: 43-48); B - cuticular lobes aspect using phase-constrast microscope; $\mathrm{C}$ - aspect of lobes using SEM.

Using SEM, Hance et al. (1998) have measured different parameters to characterize the shape of lobes (Figure 12), and only one allowed them to distinguish between the two forms: the ratio between the base of the lobe (B) and its height $(\mathrm{H})$ which was greater in the GF than in the RF (2.75 vs. 2.11).

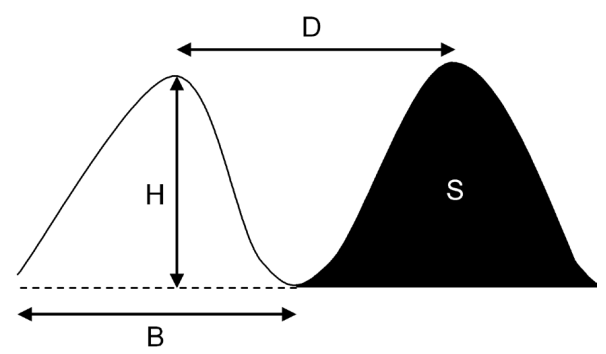

FIGURE 12: Parameters measured on the dorsal integumentary lobes: base (B), distance between the top of two lobes (D), height $(\mathrm{H})$, surface of a lobe $(\mathrm{S})$ (redrawn after Hance et al., 1998).

However the authors estimated that the lobe morphology is a difficult criterion to distinguish between the two species because they found sometimes more variations between individuals than between the two forms.

For long time, taxonomists regarded integumentary lobes as qualitative data, until Monroe (1963) first assessed lobe density and used this criterion 
to separate the two forms of T. urticae. This author found that females of the GF had 5 to 6 lobes per $10 \mu \mathrm{m}$ in average, and observed a greater lobe density in the RF than in the GF. While no mention of the value of the RF lobe density is clearly done by Monroe (1963), a new analysis of the data allows to estimate this density at about 7 lobes per $10 \mu \mathrm{m}$. Using SEM, comparable densities per $10 \mu \mathrm{m}$ were calculated in GF ( $6.4 \pm 0.8$ lobes; range: 5 to 8$)$ and RF (7.5 \pm 0.8 ; range: 6 to 9.5) by Brandenburg and Kennedy (1981), or $5.8 \pm 0.2$ lobes in the GF and $7.0 \pm 0.4$ lobes in the RF by Kuang and Cheng (1990). However Brandenburg and Kennedy's results (1981) show lobe densities confidence intervals overlapping among the two colour forms making this criterion invalid for species diagnostics (Mollet and Sevacherian, 1984). By contrast, Kuang and Cheng (1990) did not observed such overlap.

\section{Lobe shape variations}

While the lobe shape has been used to discriminate between RF and GF, intraspecific variation of the dorsal lobe shape pattern, the lobe density and the lobe development have been widely reported. When strongly developed, lobes might be semioblong to semi-circular on the GF but when a slight development is present, lobes are more oblong with more flattened upper side (Van de Bund and Helle, 1960) (Figure 13 A, B and C).
A

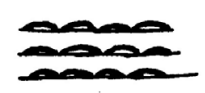

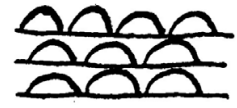

B

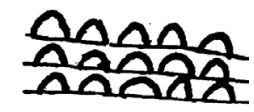

C
FIGURE 13: Variations in aspect and development of dorsal lobes in GF females of Tetranychus urticae (original drawings from C.F. van de Bund and W. Helle - 1960 - Entomol. Exp. et appl., 3: 142-156). A - less developed lobes; B - normally developed lobes; $\mathrm{C}$ - strongly developed lobes.

On RF, slightly developed lobes are mostly semicircular to rather semi-oblong but they are often triangular in case of strong development (Figure $14 \mathrm{~A}$ B). Van de Bund and Helle (1960) reported a slight development in many specimens, concluding that lobes do not allow to distinguish between the two forms (Figures $13 \mathrm{~A}, 14 \mathrm{~A}, 15$ ).

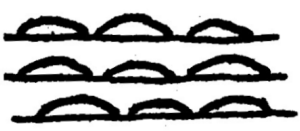

A

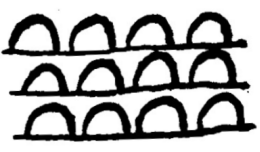

B
FIGURE 14: Variations in the aspect and development of dorsal lobes in RF females of Tetranychus urticae (original drawings from C.F. van de Bund and W. Helle - 1960 - Entomol. Exp. et appl., 3: 142-156). A - less developed lobes; B - normally developed lobes.

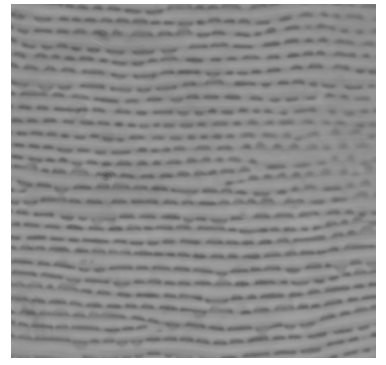

A

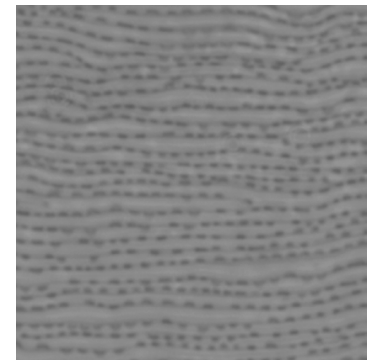

B
FIGURE 15: Appearance of less developed female dorsal lobes using phase-contrast microscope. A - in GF females of T. urticae; B - in RF females of T. urticae.

While confirmed by Monroe (1963) who also faced this problem, Dosse and Boudreaux (1963) concluded that these variations would only appear in improperly mounted specimens. However, even in well mounted specimens, variations are known to occur among populations from each of the two $T$. urticae forms (Boudreaux and Dosse, 1963b; Monroe, 1963; Dosse and Langenscheidt, 1964; Meyer, 1974; Jordaan, 1977). This leads Monroe (1963) to consider that the differences in lobe are not a consistent character of each mite form, as intra- and intervariation in the lobe characters of each mite colour overlap (Meyer, 1974; Jordaan, 1977).

Environmental factors can also modify dorsal lobe patterns. Mollet and Sevacherian (1984) have shown that the strial lobe density of the GF can change with temperature and moisture (Figure 16) and depending on the season they found specimens with intermediate lobe shape patterns. They concluded that lobe density is not a reliable morphological character for separating the two forms. 


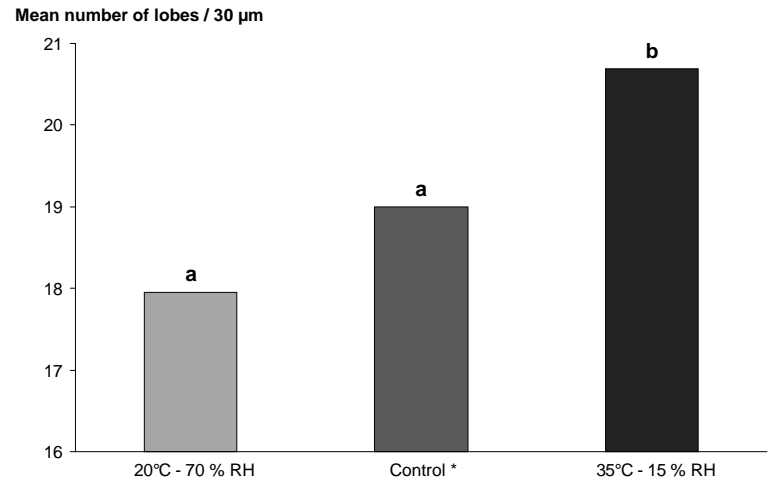

FIGURE 16: Mean number of dorsal strial lobes/30 micrometer on GF females of Tetranychus urticae reared at different temperature and humidity regimes (after Mollet and Sevacherian, 1984). Means sharing a common letter are not significantly different (Duncan's NMRT P<0.05). * Mites collected from cotton leaves and then used for experiments: their lobes were observed at the start of the experiment to be used as reference.

Likewise, the integument of hibernating GF females differs from that of active females (Pritchard and Baker, 1952) and is characterised by a solid-type striae (smooth striation devoid of lobes) (Figure 17 A).

This striation pattern can also be found in active GF females when during their development a single instar has been exposed to environmental conditions which induced diapause (Parr and Hussey, 1966). During winter months, the lobes of the RF tend to be wider and rounded resembling those of the GF (Boudreaux and Dosse, 1963a; Dosse, 1966; Meyer, 1974; Carbonnelle and Hance, 2004). As in diapausing or hibernating females of the two forms the integumentary striae is smooth (Figure $17 \mathrm{~B}, \mathrm{C}$ ) or with incompletely formed lobes, many authors emphasized that they cannot be separated using this morphological trait (Van de Bund and Helle, 1960; Dosse, 1966; Dosse and Musa, 1967; Meyer, 1974; Jeppson et al., 1975).

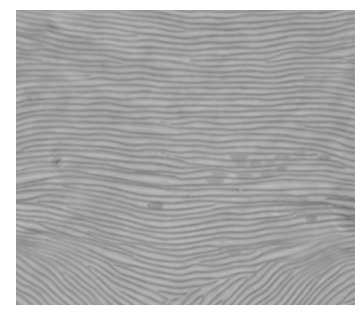

A

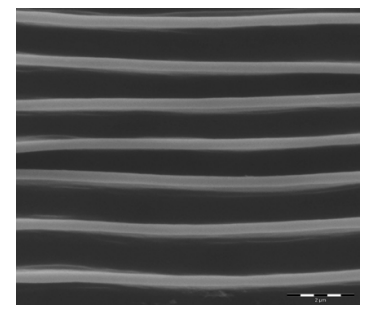

B

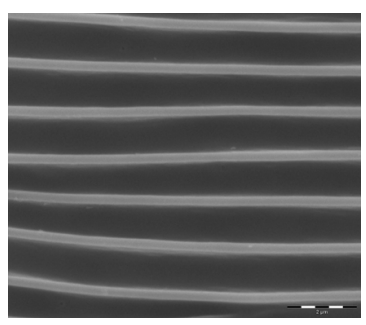

C

FIGURE 17: Smooth dorsal striation of hibernating females. A GF females of Tetranychus urticae using phase-contrast microscope; B - GF females of T. urticae using SEM; C - RF females of $T$. urticae using SEM.

\section{Genetic determinism of the lobe shape}

Observations concerning the determinism of the lobe shape are conflicting. According to Boudreaux (1956), the dorsal lobes in F1 hybrids are mostly triangular in shape to semi-circular like those found in the RF but occasional oblong lobes typical of the GF can also be observed.

Hybridisation tests between the GF and the RF led Boudreaux (1956) and Dupont (1979) to conclude on the dominance of the triangular lobes over the oblong ones. Conversely, Monroe (1963) produced F1 hybrids that usually possessed dorsal integument lobes similar to those of the GF, concluding that the rounded lobes typical of the GF would usually be dominant over the pointed triangular lobes of the RF which would be recessive (Boudreaux, 1963; Monroe, 1963). However, Jordaan (1977) obtained a different result because most of the F1 females she observed had dorsal lobes of intermediate form. In F2 females Monroe (1963) and Jordaan (1977) found great variations regarding lobe shape and density. 
Lobe shape to distinguish between the two colour forms

When Boudreaux (1956) reinstated T. cinnabarinus (the RF of T. urticae) he associated the body colour of the mite with a type of dorsal lobe shape. However, a red Tetranychus (T. urticae forma dianthica Dosse, 1952) found in German greenhouses and similar to the RF exhibited broad integumentary dorsal lobes typical of those usually present in the GF (Boudreaux and Dosse, 1963b; Dosse and Boudreaux, 1963). When crossbreeding this population with a strain of the RF they freely interbreed, despite a partial reproductive isolation (Dosse, 1963), supporting their synonymy (Pritchard and Baker, 1952; Boudreaux, 1956, 1959).

The hypothesis of hybridization in naturae (vs. laboratory conditions) was put forward to explain these data (Boudreaux and Dosse, 1963b; Dosse and Boudreaux, 1963; Jordaan, 1977) which could explain why several other populations bearing mixed lobe and colour characteristics have been observed (Pritchard and Baker, 1952; Van de Bund and Helle, 1960; Dosse and Boudreaux, 1963; Dosse, 1964; Dosse and Langenscheidt, 1964; Parr and Hussey, 1966). The case of T. urticae forma dianthica reveals that the use of lobe shape to separate the two forms of T. urticae might not be valid because the triangular shape of the dorsal lobes is not always linked to the red colour of the mite and as also observed in green hybrid females which bear typical lobes of the RF (Jordaan, 1977). Another exception concerning the correlation between the dorsal lobe shape and the body colour of the mite is reported from greenhouses where some GF populations with dorsal lobes were closer to RF than to other GF mites (Zhang and Jacobson, 2000). Likewise, females of these GF populations had a particular foreleg chaetotaxy (see "Leg chaetotaxy" section below) leading the authors to consider them as T. cinnabarinus $(=\mathrm{RF})$.

\section{New data}

The analysis of a collection of mounted T. urticae slides, revealed specimens with poorly developed lobes in the majority of RF but only occasionally in the GF examined, as having been previously reported by Van de Bund and Helle (1960). In partic- ular, the lobes shown in figure $11 \mathrm{~B}$ were rarely observed on our RF females. The typical lobes shown in this figure were present in only one in four females collected together in the same rearing unit kept in the laboratory. The three other females carried poorly developed lobes. It was then impossible to discriminate among RF and GF mites based on this criterion. Among females bearing well developed dorsal lobes, we also found lobe shape variations between populations of a given form. Like Zhang and Jacobson (2000) we faced the apparent contradiction between the dorsal lobe pattern and the body colour when analysing GF females collected in Tunisia. Despite their green colour, they had a dorsal striation with a majority of small quite well separated rounded lobes, sometimes triangularly rounded and with rare oblong lobes (Figure 18).

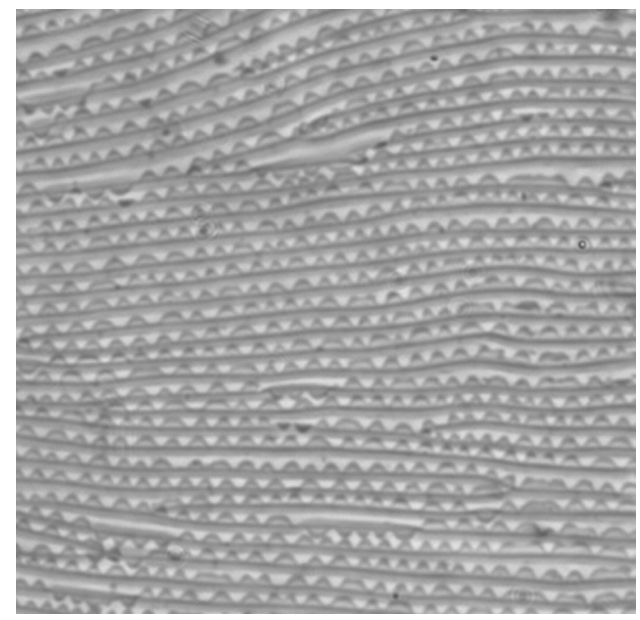

FIGURE 18: Atypical dorsal lobe pattern present in green Tetranychus urticae females of a population bearing additional setae on tarsus and tibia of the front leg.

Like the specimen collected by Zhang and Jacobson (2000) these females had a particular leg chaetotaxy. These data highlight that body colour and lobe shape might be disconnected.

The lobes we observed on dorsal striation of F1 females and of hybrid females of re-established population (F20-30), like reported by Dupont (1979), were closer to those of RF and were mostly triangular to triangularly rounded (Figure 19). 


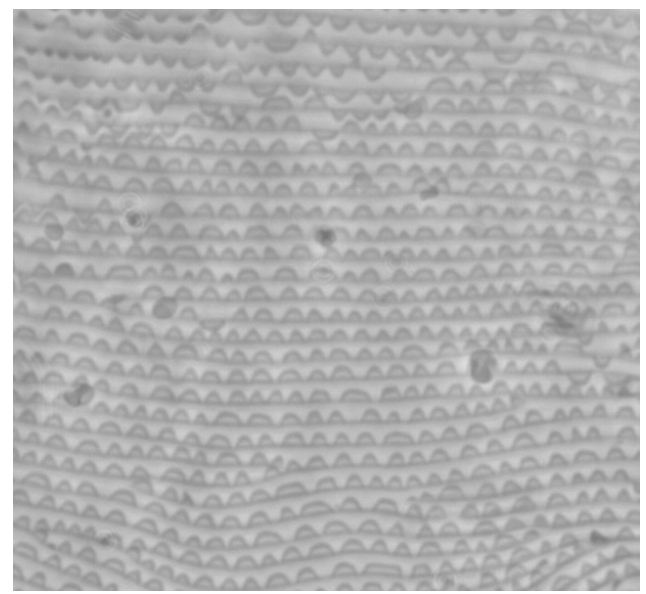

FIGURE 19: Dorsal lobe aspect observed on F20-30 hybrid female of Tetranychus urticae.

In conclusion, the dorsal integument lobes is a morphological character often included in descriptions of Tetranychus species and in the identification keys made by numerous acarologists. In this section we have reported different factors that might affect proper observation and distort their shape. As a consequence, both inter- and intra-population variations of the size and/or shape of this trait might occur, sometimes leading to partial overlapping among the two forms of T. urticae, making it uneasy to use to distinguish between GF and RF (Pritchard and Baker, 1952; Van de Bund and Helle, 1960; Dosse, 1964; Parr and Hussey, 1966; Jordaan, 1977). Special attention must be given to the global dorsal lobe pattern (i.e. the frequency of the two types of lobes) rather than to the presence or not of one type of dorsal lobe.

The lack of complete link between the type of dorsal lobes and the body colour of the mite also reduce the reliability of this character to separate the two forms of T. urticae. However, Zhang and Jacobson (2000) increased the importance of the lobe shape dorsal striation over the body colour to separate the GF from the RF, the latter being considered as T. cinnabarinus, because they found a better correlation between this criterion and other morphological characters to separate the two forms of T. urticae (see "Other morphological characters" section below).

\section{Shape of the aedeagus}

According to Boudreaux (1956), who considered the GF and the RF as distinct species and reinstated T. cinnabarinus (RF), the aedeagus of the GF bears a knob with an anterior and a posterior projection, both small and rather acute, a dorsal margin of the knob broadly rounded or somewhat obtusely angulate and the axis of the knob parallel to the axis of the shaft (Figure $20 \mathrm{~A}$ ). By contrast, RF has an anterior projection of the knob slightly rounded and a posterior one acute, a knob dorsal surface obtusely angulate and the axis of the knob that always forms a slight angle with that of the shaft (Figure 20 B).

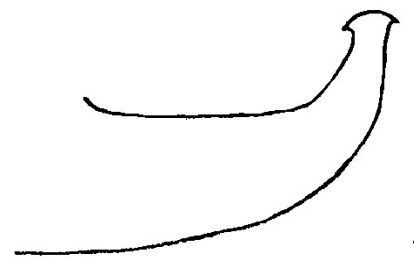

A

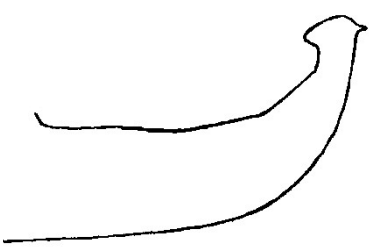

B
FIGURE 20: A - Aedeagus of the GF male Tetranychus urticae; B - aedeagus of RF male of T. urticae (original drawings from H. Bruce Boudreaux - 1956 - Ann. Entomol. Soc. Am., 49: 43-48).

However, the separation of the two forms might be misleading because several noticeable differences in description of the aedeagi have been reported: Saba (1975) found that the axis of the knob of the aedeagus forms an angle with the axis of the shaft which is greater in the GF than in the RF (Figure $21 \mathrm{~A}$ ). According to Kuang and Cheng (1990) the aedeagus knob of RF is larger than that of GF and their drawings exhibit a knob dorsal margin convex in the two species (Figure $21 \mathrm{~B}$ ). In addition, aedeagal variations between and among populations are also reported by several authors (Boudreaux and Dosse, 1963b; Meyer, 1974; Zhang and Jacobson, 2000). The drawings of aedeagi of $T$. cinnabarinus by many authors clearly illustrate this variability and the difficulty to link the aedeagus shape to one of the colour forms of T. urticae. The shape of the aedeagus knob sometimes overlaps between the two forms: an acute anterior projection can be present on the aedeagi of both colour forms (Figure 
Green form of T. urticae
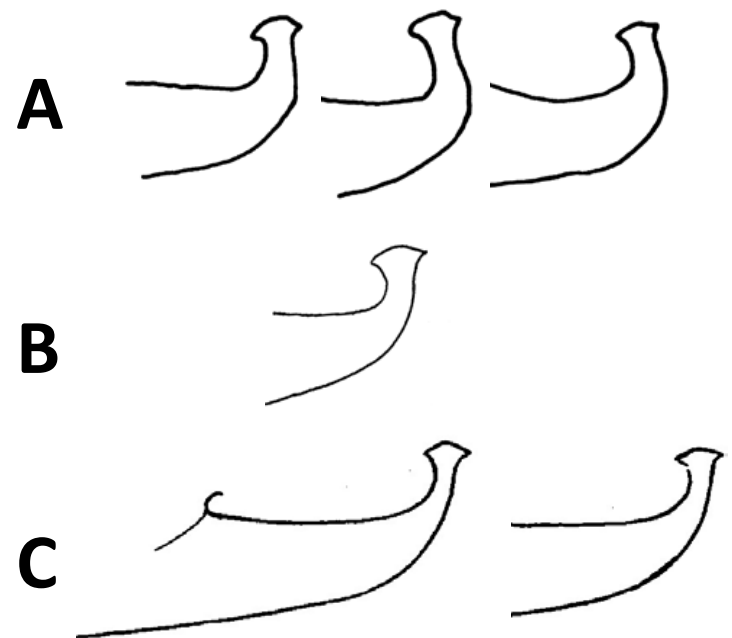

D

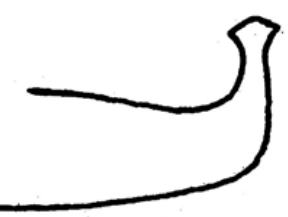

E

$\mathbf{F}$

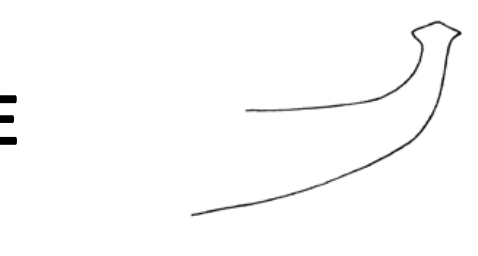

\section{F}

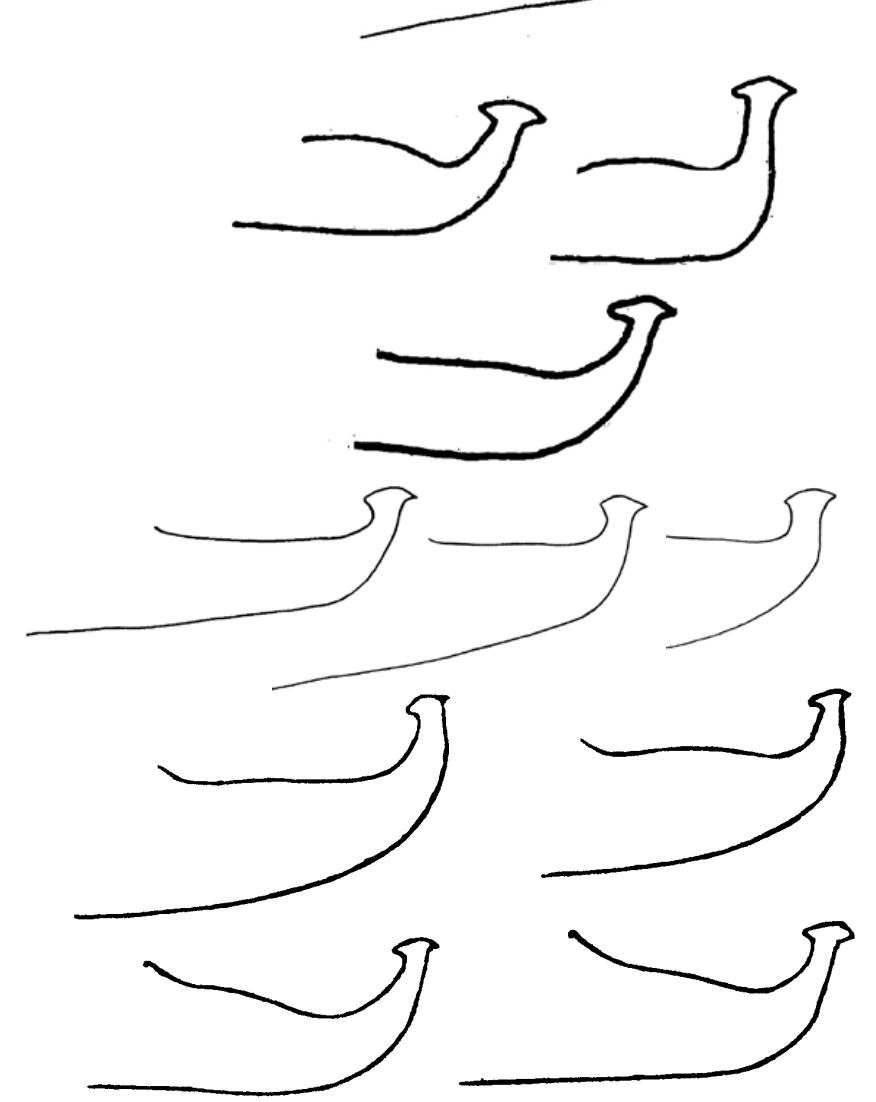

FIGURE 21: Variations found in the aedeagi of the GF (left) and of the RF (right) of Tetranychus urticae. A - drawings from F. Saba 1975 - Ann. Entomol. Soc. Am. 1975, 68: 797-800; B - drawings from H.Y. Kuang and L.S. Cheng - 1990 - Acta Entomol. Sinica, 33: 109-116; C - drawings by E.W. Baker and A.E. Pritchard - 1960 - Hilgardia, 29: 455-574, copyright 1960 Regents of the University of California; D - drawings from C.F. van de Bund and W. Helle - 1960 - Entomol. Exp. et Appl., 3: 142-156; E - drawings from M.K.P. Smith Meyer - 1974 - Entomology Memoir, Department of Agricultural Technical Services, Republic of South Africa: 1-291; F drawings from E.A. McGregor — 1950 - Am. Midland Natural., 44: 257-420. 
$21 \mathrm{~B}, \mathrm{D}, \mathrm{E})$ and the aedeagal knob axis can be parallel to the axis of the shaft in the two forms (Figure 21 D-E). Moreover, typical knob characteristics of a given colour are sometimes absent in that form but present in the other. This is illustrated by Meyer's drawings (1974) with an obtuse angulation of the dorsal margin of the aedeagal knob absent on the RF but present on the GF, whereas the rounded dorsal margin is present on the RF (Figure $21 \mathrm{E}$ ). Likewise, the knobs of the aedeagi of the GF described by Saba (1975) and Kuang and Cheng (1990) clearly form a slight angle with the axis of the shaft but not in most of RF aedeagi (Figure $21 \mathrm{~A}-\mathrm{B}$ ). Sometimes, the heads of the aedeagi of the two colour forms are very similar as observed in Boudreaux and Dosse's pictures (1963b) (Figure $22 \mathrm{~A}-\mathrm{B})$. forms

Aedeagus shape to distinguish between the two colour

Many papers aimed at distinguishing between the two forms of T. urticae do not evoke the shape of the aedeagus. This tend to show that the taxonomical value given to the aedeagus shape to distinguish between the two forms of $T$. urticae varies among authors and also that for many of them other morphological and biological criteria are more efficient and more reliable.

Despite the differences in the aedeagi of the two forms, as emphasized Boudreaux (1956), GF males are almost indistinguishable from RF ones. As differences are minute between the aedeagi of the two forms (Dosse and Boudreaux, 1963; Saba, 1975) or not consistent (Hatzinikolis, 1970), these authors considered that the shape of the aedeagus is not fully reliable for the separation of the two colour forms of T. urticae. Likewise, female morphological characters such as the body colour and the shape of the dorsal integumentary lobes are the only reliable traits allowing to distinguish between the GF and the RF (Boudreaux and Dosse, 1963b). For other authors, however, the aedeagus remains the most useful character for species identification (Dillon, 1958; Meyer, 1974; Van de Bund and Helle, 1960; Zhang and Jacobson, 2000).
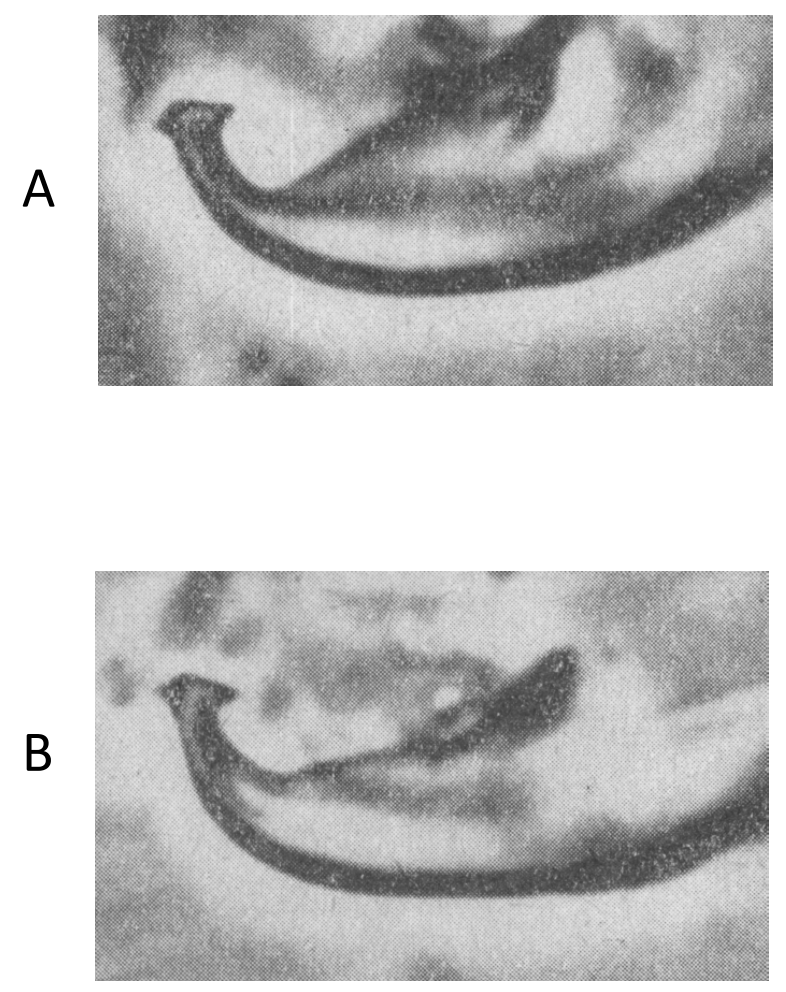

FIgURE 22: Pictures of the aedeagi of the GF (A) and RF (B) of Tetranychus urticae both having acute anterior and posterior projections, angulate dorsal margin and a knob axis forming an angle with the axis of the shaft (original pictures from Boudreaux and Dosse (1963b) with permission from Acarologia).

\section{New data}

All the aedeagi from RF mites that we have examined under microscope were close in shape to those described and drawn by Boudreaux (1956) (Figure 23 A). However, in several males of each of the RF samples, the inner projection of the knob was slightly acute (Figure 23 B) and the axis of the knob did not systematically form a slight angle with the shaft (Figure $23 \mathrm{C}$ ). The differences are more obvious between the descriptions of the aedeagus of the GF found in the literature cited above in this section and the aedeagi of the specimens that we have observed. With the exception of 1 or 2 specimens (Figure $23 \mathrm{D}$ ), none of these aedeagi bore the typical more or less symmetrical knob with two comparable acute projections and a rounded dorsal margin as figured by Boudreaux (1956). In most of the cases examined they closely resemble those of the 

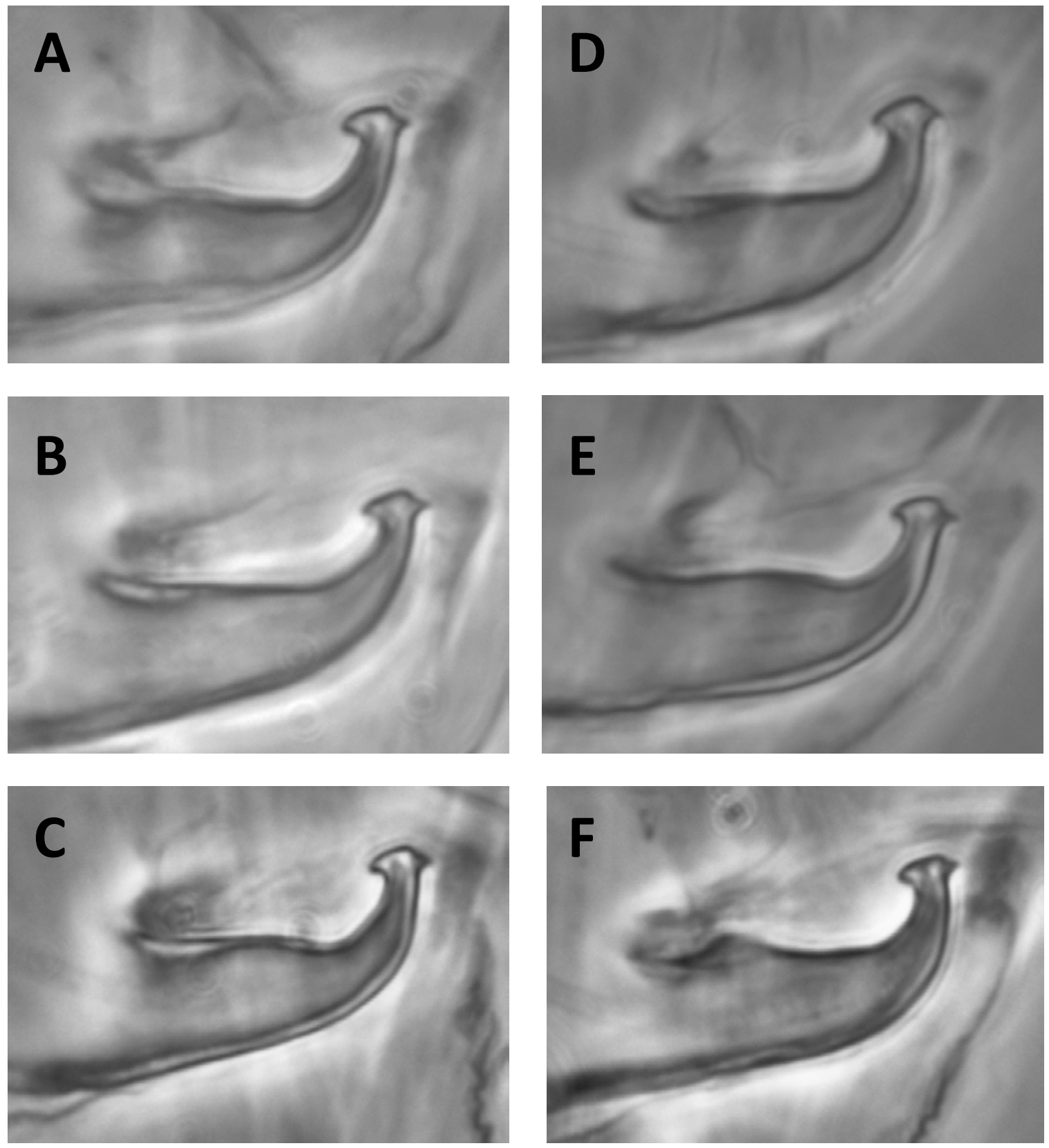

FIGURE 23: A - Typical aedeagus of the RF of Tetranychus urticae found in two populations collected in Spain and south of France; B aedeagus of the RF bearing an acute anterior projection; $\mathrm{C}$ - aedeagus of the RF showing no obvious angle between the knob axis and the shaft axis; D - aedeagus of the GF of T. urticae having the characteristics reported by Boudreaux (1956); E - common aedeagus of the GF observed in three populations originating from Canada, Scotland and France; F - aedeagus of the GF bearing a knob with a rounded innate projection and the axis of the knob forming an obvious angle with the shaft axis. 
$\mathrm{RF}$ and were closer to the RF than to GF figured by Boudreaux (1956) (Figure 20). They have an asymmetrical knob with a dorsal margin more angulate than rounded. The posterior projection is smaller and more acute than the anterior one which is somewhat rounded (Figure 23 E-F). Sometimes the axis of the knob forms a slight angle with the axis of the shaft (Figure $23 \mathrm{~F}$ ). They are similar to the aedeagi of T. urticae figured by Ehara and Gotoh (1996). A slight difference between the aedeagi of the two colour forms of our samples lies in the inner projection which seems to be slightly more rounded in the RF than in the GF.

The variability of the shape of the aedeagus in the two colour forms detected by several acarologists, in particular the differences in the size of the aedeagi of both forms of T. urticae reported by Kuang and Cheng (1990) and also in the specimens that we examined for this work, prompted us to compare the aedeagi of males of the 5 strains of the two colour forms (Table 2). Among the five parameters measured (see Figure 1), significant differences were found between three of them (Table 4): the length of the aedeagus $\mathrm{knob}\left(F_{4,71}=11.67, P<0.0001\right)$, the hight of the hook $\left(F_{4,67}=5.27, P<0.0009\right)$ and the angle formed between the axis of the knob and the dorsal margin of the aedeagal shaft $\left(F_{4,69}=3.04\right.$, $P=0.023)$. However, the angle between axis of knob and aedeagal shaft and the width of neck of the aedeagal hook, do not significantly differ between populations $\left(F_{4,67}=2.45, P=0.132 ; F_{4,70}=0.68, P=0.607\right.$ respectively) (Table 4).

The absence of significant differences between populations for the angle formed by the axis of the knob and the aedeagal shaft seems to be due to great intra-population variability, whatever the body colour of the mite is. For example, in males belonging to the RF from France, a quarter of them bears a knob aedeagus whose axis is parallel to that of the shaft. Thus, this criterion which is sometimes used to separate the two colour forms, appears to not to be fully reliable due to intra-population variations. Despite differences found in three morphological characters of the aedeagus, none of them allow to distinguish all the populations of the RF from all those of GF. Indeed, several populations seem to be morphologically "intermediate". This is the case of the GF Scotland population for the length of the aedeagal knob (Table 4). Individual variability observed within populations and variability between populations of a given colour form demonstrate that there is no systematic and obvious clearcut difference in the aedeagus shape. Thus, the male aedeagus does not allow separating reliably the two forms of T. urticae.

However, this polymorphism illustrated in Figure 21, which is unique in the genus Tetranychus, is problematic because since the works of Ewing (1913) and Pritchard and Baker (1955) the role of the aedeagus for species diagnostics in the Tetranychus genus has been strongly put forward. It is difficult to know whether this variability is mainly due to in-

TABLE 4: Measures of aedeagal features (mean \pm SE) in 3 populations of the green form (GF) and 2 of the red form (RF) of Tetranychus urticae.

\begin{tabular}{lccccc}
\hline $\begin{array}{c}\text { T. urticae } \\
\text { populations }\end{array}$ & Knob length $(\mu \mathrm{m})$ & Neck width $(\mu \mathrm{m})$ & Hook high $(\mu \mathrm{m})$ & $\begin{array}{c}\text { Angle with shaft } \\
\text { axis }\left({ }^{\circ}\right)\end{array}$ & $\begin{array}{c}\text { Angle with shaft } \\
\text { dorsal margin }\left(^{\circ}\right)\end{array}$ \\
\hline GF France & $2.46 \pm 0.01(15)^{*} \mathrm{a}$ & $1.37 \pm 0.02(15) \mathrm{a}$ & $3.73 \pm 0.08(14) \mathrm{b}$ & $3.87 \pm 1.02(15) \mathrm{a}$ & $9.22 \pm 1.33(14) \mathrm{ab}$ \\
GF Canada & $2.52 \pm 0.02(15) \mathrm{b}$ & $1.37 \pm 0.01(14) \mathrm{a}$ & $3.13 \pm 0.08(14) \mathrm{a}$ & $1.85 \pm 0.64(15) \mathrm{a}$ & $7.67 \pm 1.00(15) \mathrm{a}$ \\
GF Scotland & $2.57 \pm 0.03(15) \mathrm{bc}$ & $1.39 \pm 0.02(15) \mathrm{a}$ & $3.79 \pm 0.10(15) \mathrm{b}$ & $2.10 \pm 0.68(15) \mathrm{a}$ & $8.87 \pm 1.11(15) \mathrm{ab}$ \\
RF Spain & $2.59 \pm 0.01(16) \mathrm{c}$ & $1.40 \pm 0.01(16) \mathrm{a}$ & $3.94 \pm 0.07(16) \mathrm{b}$ & $3.14 \pm 1.08(16) \mathrm{a}$ & $11.26 \pm 1.52(16) \mathrm{ab}$ \\
RF France & $2.63 \pm 0.02(15) \mathrm{c}$ & $1.40 \pm 0.05(15) \mathrm{a}$ & $3.68 \pm 0.27(13) \mathrm{b}$ & $4.88 \pm 1.05(15) \mathrm{a}$ & $13.59 \pm 1.55(14) \mathrm{b}$ \\
\hline
\end{tabular}

* Number of mite observed

Means sharing a different letter within a column are significantly different (ANOVA followed by Student-Newman-Keuls test; $P<0.05)$ 
trinsic morphological differences and/or to the observation under microscope of specimens on edge because the aedeagal knob is a roughly lenticular disc and a slight tilt may influence its observation (Dosse and Boudreaux, 1963). In conclusion, the polymorphism observed in the aedeagus of T. urticae could be partly responsible for the denomination of polytypic-species given to the two colour forms by Pritchard and Baker (1955) and Meyer (1987). In addition to other characters, this potential variability has also certainly reinforced the opinion of several taxonomists to consider T. cinnabarinus as a synonym of T. urticae. It is important to note that acarologists such as Pritchard and Baker (1955), Meyer (1987) and Ehara (1999) have described the aedeagal knob of T. urticae (including the two colour forms) as small, forming sometimes a small angle with the axis of the shaft and bearing a dorsal margin as well as the anterior and posterior projections that vary considerably.

\section{Leg chaetotaxy}

The Tetranychus sensu stricto females (Tuttle and Baker, 1968) usually bear 14 tactile setae and one solenidion on tarsus I and 9 tactile setae and one solenidion on tibia I. Additional setae observed on leg I tarsus and tibia of Tetranychus specimens have been reported and used to separate GF and RF.

In 1950 McGregor described a new species of red spider mite named T. multisetis. This mite only differs from the RF by its first leg chaetotaxy: one or two extra chemosensory setae (solenidia) proximad to the proximal set of duplex setae are added to the tarsus and tibia (Figure 24 A-B). Later, several crossing experiments have shown that this species and the RF freely interbreed (Davis, 1952; Boudreaux, 1956; 1959; Helle and Van de Bund, 1962; Dosse, 1963). Crosses also revealed that the inheritance of the foreleg setation is unique (Table 5): it is transmitted from mother to daughter regardless to the

TABLE 5: Inheritance of the leg setation on tarsus and tibia of the frontleg in relation to the body colour in crossing experiments between the two colour forms of T. urticae (after Keh, 1952). A and B represent reciprocal crosses.

\begin{tabular}{|c|c|c|c|c|}
\hline \multirow[t]{2}{*}{ A } & \multicolumn{2}{|c|}{ Parental Cross } & \multirow[b]{2}{*}{$\mathrm{F} 1$} & \multirow[b]{2}{*}{ F2 } \\
\hline & $\begin{array}{c}\text { Red (R) } \\
\text { form }\end{array}$ & $\begin{array}{l}\text { Green }(G) \\
\text { form }\end{array}$ & & \\
\hline & $q$ & $\hat{0}$ & 우 & q \\
\hline Body colour & $\mathbf{R}$ & G & $\mathrm{R}$ & $\mathrm{R}$ \\
\hline $\begin{array}{c}\text { Setae }^{1} \text { on female leg I: } \\
\text { Tarsus - Tibia }\end{array}$ & $6-13$ & $4-10$ & $6-13^{2}$ & $6-13^{2}$ \\
\hline
\end{tabular}

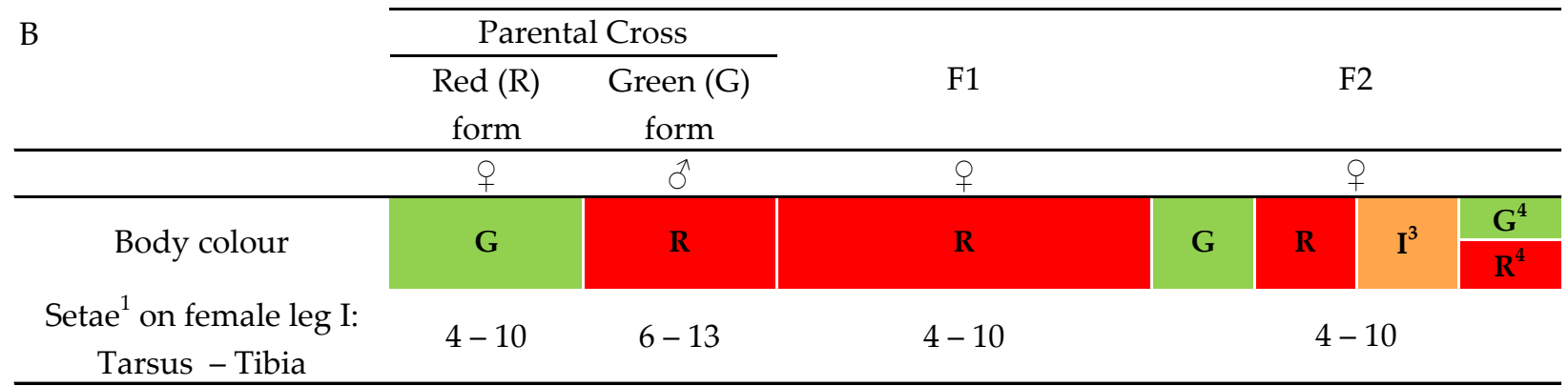

\footnotetext{
${ }^{1}$ Tarsal setae numbers refer to the number of setae proximal to proximal duplex setae.

${ }^{2} \mathrm{~A}$ few females bore 5 to 7 setae on tarsus I and 12 to 14 setae on tibia I.

${ }^{3}$ Intermediate body colour.

${ }^{4}$ Color changes with age: green females turn red.
} 

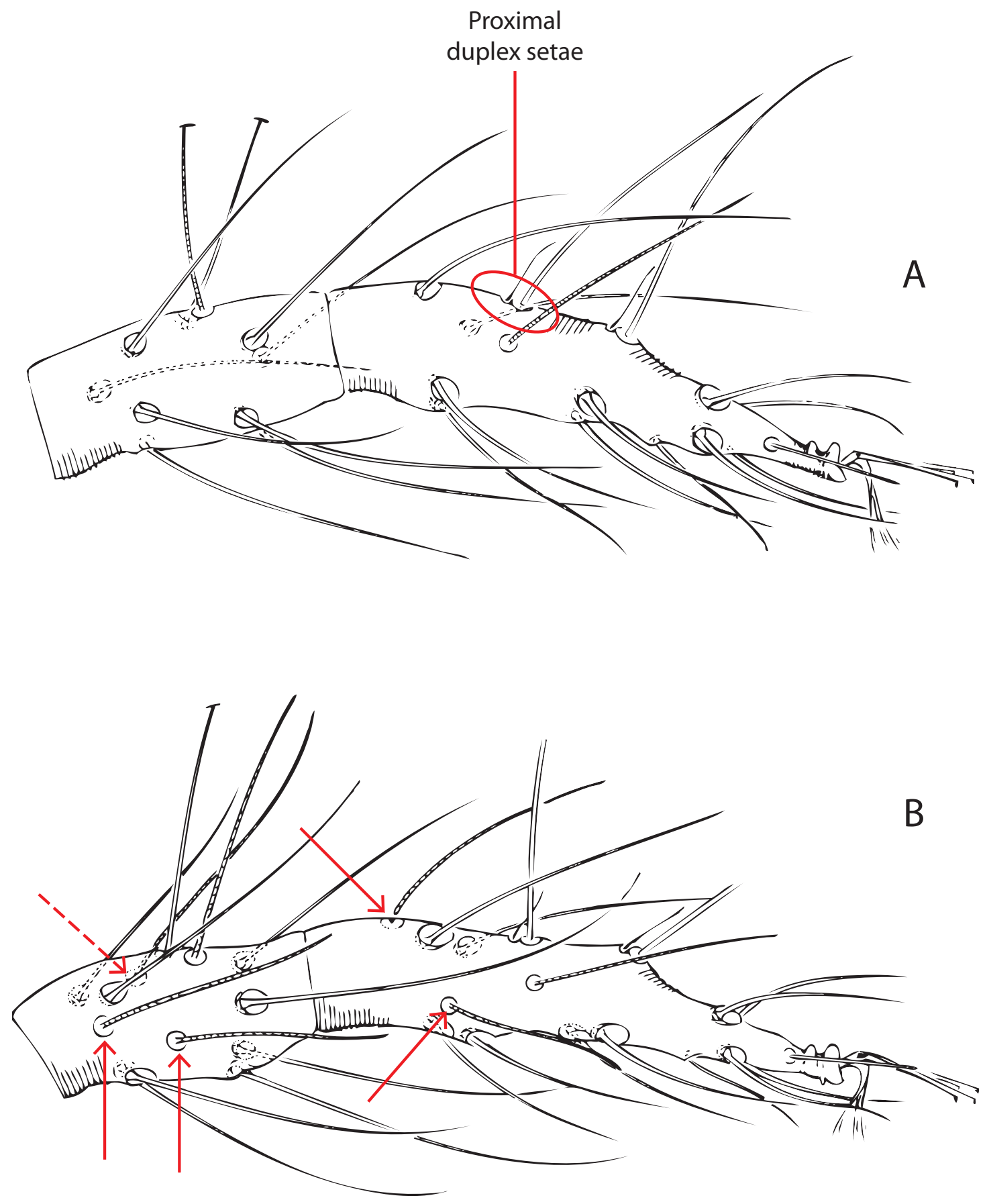

FIGURE 24: Chaetotaxy of female tarsus and tibia of the first leg. A - Red form (RF) of Tetranychus urticae (T. cinnabarinus sensu Boudreaux, 1956); B - T. multisetis (=polychaete form of the RF). Additional solenidia are indicated by arrows (A and B original drawings by Baker and Pritchard - 1960 - Hilgardia, 29: 455-574, copyright 1960 Regents of the University of California).

male used in crosses. Breeding experiments between this species and the GF confirmed the pre- vious results but also showed that foreleg hypertrichy and the body colour of mites are not linked 
(Keh, 1952) (Table 5). Boudreaux (1959) who has studied the genetics of the fore tibia and tarsus hypertrichy concluded that it would be caused by the absence of a "viruslike transovarian substance" present in some populations. Taken together, these results allowed to conclude that $T$. multisetis was a synonym of the RF and as a consequence that the leg setation was of no value to characterize one of the carmine forms (Pritchard and Baker, 1952; Helle and Van de Bund, 1962). By contrast, populations of the GF whose females' front leg chaetotaxy was similar to that of the polychaete form of the RF were also reported (Boudreaux, 1956; Dillon, 1958; Helle and Van de Bund, 1962; Rambier, 1965; Hatzinikolis, 1970). Foreleg hypertrichy was also found in T. gloveri Banks, 1900 with samples including polychaete specimens among individuals bearing the usual chaetotaxy, corroborating the taxonomical invalidity of this morphological criterion and its use to separate the two colour forms of $T$. urticae (Boudreaux, 1958b; 1959).

Nevertheless, hypertrichy found in the front legs of some specimens of the RF but not in the GF, was retained as an additional tool to separate the GF from the RF (Kuang and Cheng, 1990). In agreement with this work, Zhang and Jacobson (2000) went further in considering this morphological trait to be a more reliable character than the colour of the mite to separate the two colour forms of T. urticae. The latters did not separate the GF from the RF by their body colour but by the chaetotaxy of the front leg combined with the dorso-hysterosomal striation lobe shape pattern. They concluded to have obtained a better correlation between several morphological characters and the species designation when they separated the 2 colour forms on the basis of this combination of characters (see section "Other morphological characters" below). These authors concluded that polychaete green and red mites belong to $T$. cinnabarinus because both bear a similar dorsal lobe pattern. Only females bearing the usual number of setae on the first leg and dorsal lobes rounded or oblong can then be considered as T. urticae. Moreover, despite the observations concerning the matriclinous inheritance of leg hypertrichy (Boudreaux, 1958b; 1959) and leg hypertrichy being also found in some specimens of T. gloveri, Zhang and Jacobson (2000) concluded that the addition of male solenidia, i.e. hypertrichy, on the female first leg is apomorphic as it is not observed in the GF (green coloured females bearing rounded lobes on their dorsohysterosomal striation, see next section) nor in other related species.

\section{New data}

We have found a polychaete population of the GF whose females bear the usual lobe pattern in the dorsohysterosomal striation (Figure 25). This result contrasts with the observations of Zhang and Jacobson (2000) who stated that leg hypertrichy was linked to more or less triangularly rounded dorsal lobes. The argument consisting in separating the two taxa by the combination of the foreleg chaetotaxy and the shape of the dorsal lobes, is invalid because these characters are not linked. This is also the case for the RF described by Dosse (1952) and called T. urticae forma dianthica.

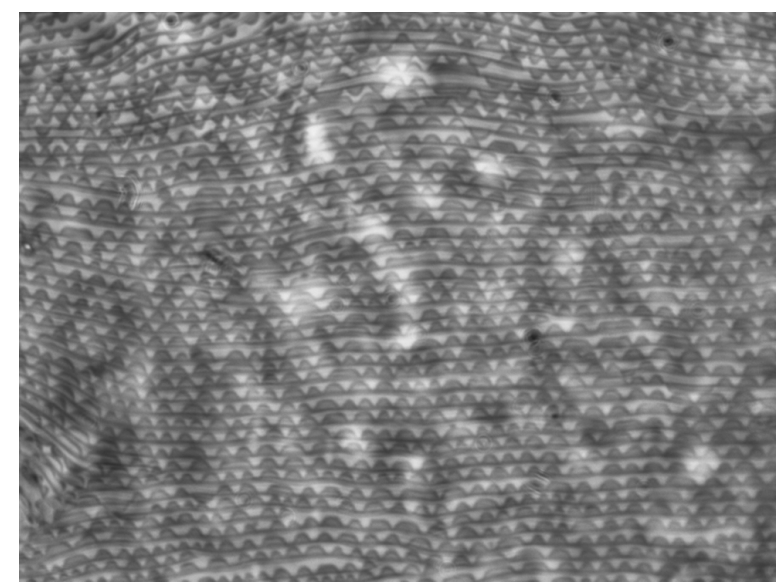

FIGURE 25: Cuticular lobe pattern present on the dorsal striation of a polychaete french population of the GF of Tetranychus urticae showing rounded and oblong dorsal lobes.

In conclusion, according to the results obtained by Davis (1952), Keh (1952) and Boudreaux (1959) on the heritability of the hypertrichy of the first leg and to the explanation of these results by the study of Boudreaux (1959), who concluded that setae transmission does not depend on genetic mechanism but on cytoplasmic transmission and, as the front leg hypertrichy can be found in both females 
of the GF (green females bearing the usual dorsal lobe pattern) and of the RF but also in females of T. gloveri, the presence of extra setae on the forelegs is not distinctive of species but more probably results of a cytoplasmic factor. As a consequence, this criterion is of no value to support the taxonomical separation of the GF from the RF.

\section{Other morphological characters}

Zhang and Jacobson (2000) have tested the possibility to use several morphological characters to improve and validate the separation between the two forms of T. urticae. They have examined seven different characters in specimens from greenhouse tomato crops in United Kingdom (Figure 26). The values of these characters have been analysed using ANOVA to assess their variations between and within each colour form when species are defined according to their body colour (green $v s$ red) and when mites are grouped according to their front leg chaetotaxy (normal chaetotaxy vs hypertrichy) whatever their body colour. When mites are grouped according to their body colour they observed significant differences between red and green mites for 3 characters and variations are more often significant within colour form than between colour forms (Figure 26 A). When mites are grouped according to their type of leg chaetotaxy (T. urticae bearing the usual number of setae on tarsus I and tibia I and T. cinnabarinus corresponding to green and red individuals with hypertrichy and dorsal lobes more triangular than rounded) they emphasized that their results showed more significant differences between the two groups: significant differences between groups are found in 4 characters and, for these characters, variations among forms are less significant than interspecific ones (Figure 26 B). Within specimens collected in UK the colour of the mite is poorly correlated with the differences found in other morphological characters and thus they questioned the use of this criterion to separate the two species. They stated that the additional characters studied are better correlated with the differences found in the leg chaetotaxy and in the dorsohysterosomal lobe pattern and as a consequence they could be readily used to separate $T$. urticae from T. cinnabarinus.
In this study, whatever the criterion used to characterise the two forms of T. urticae (body colour vs. front leg chaetotaxy), the additional morphological characters seem to be too variable within each colour form to be used as additional tools to separate the two colour forms. Indeed, even when mites are separated by leg chaetotaxy, intra-group variations are more important (significant with 5 characters) than the interspecific one (significant with 4 characters) (Figure $26 \mathrm{~B}$ ). These data reveal a little bit more the difficulty to find obvious morphological clear-cut differences to separate the colour forms because of the great variation found among each character.

Moreover, Zhang and Jacobson (2000) have performed their measurements on females collected in greenhouse tomato crop in UK only. As a consequence, the potential variations due to host plants and to geographical origins in the two forms were not assessed in this study. Furthermore, we have seen in the previous section (see "Leg chaetotaxy") that the use of the foreleg chaetotaxy to distinguish between the GF and the RF is not valid and that polychaete females can bear lobes on dorsal striation that are similar to those observed on green T. urticae bearing the usual chaetotaxy (Figure 25). Thus, the differences they have observed cannot be used to consider the two colour forms as two separated species.

\section{Biological Characters}

\section{Breeding}

Another issue, which has been written about extensively, is the ability of crossing between the two forms. It is generally reported that only the first mating is effective, later ones are not (Helle, 1967). In addition, many authors like Smith et al. (1969) and Dieleman and Overmeer (1972) report the preference of females to mate with their one lineage. Helle and van de Bund (1962) and Hussey and Parr (1963) also report the frequent sibmatings. All these comportments lead to rapid isolation of populations, sometimes accelerated by host plant selection (Perrot-Minnot et al., 2002). Thus, inter-strain incompatibility is very frequent and can occur on even short distance, less than $10 \mathrm{~km}$ (Helle and 

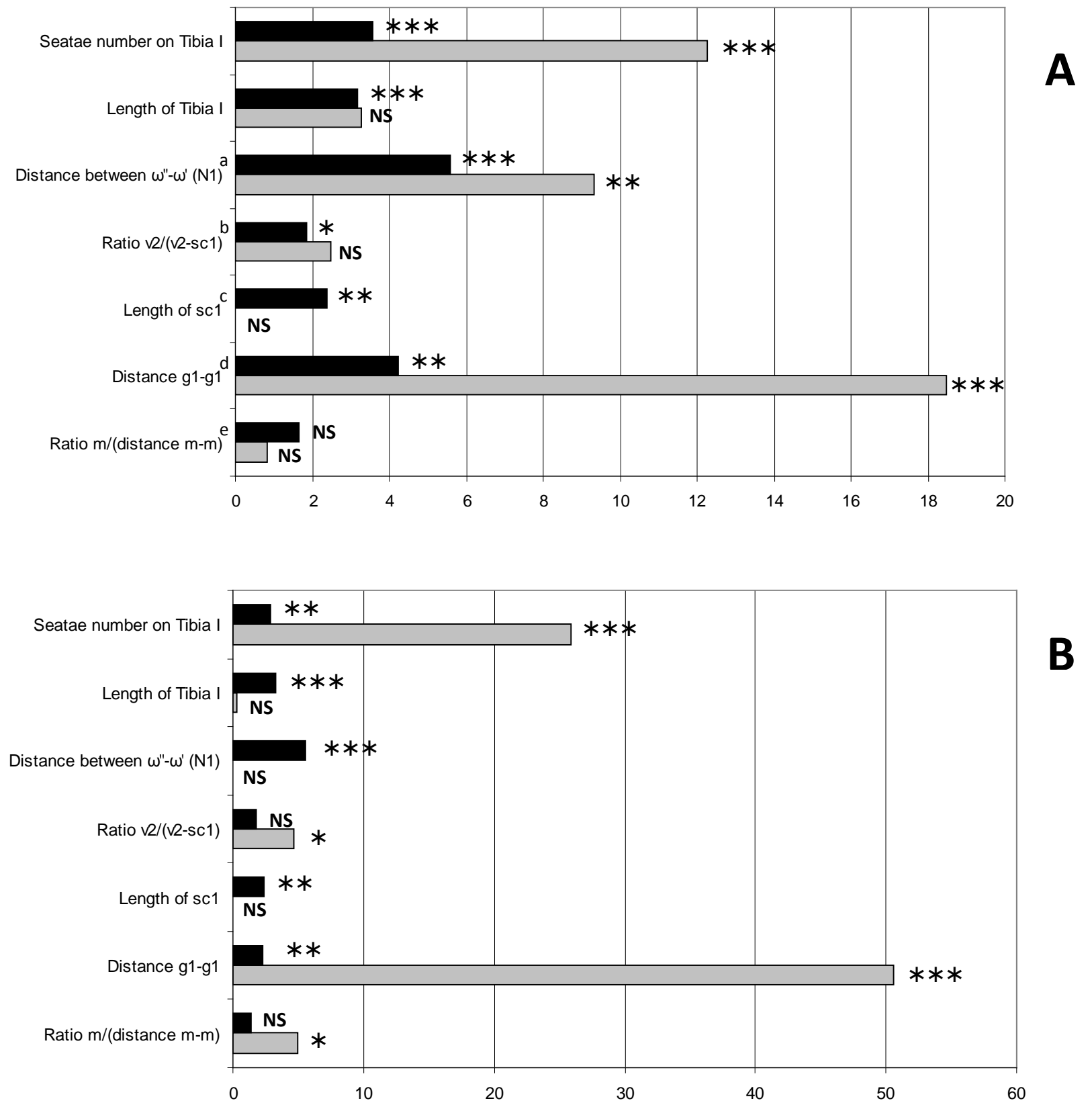

Intra-group variations

Inter-group variations

NS for not significant at $P=0.05 ; *$ for $P<0.05 ; * *$ for $P<0.01 ; * * *$ for $P<0.001$

FIGURE 26: F-values from ANOVA of six morphological characters showing intraspecific and interspecific differences between Tetranychus urticae and T. cinnabarinus specimens when grouped according to their body colour (A) or to their front leg chaetotaxy (B) (after Zhang and Jacobson (2000)). 
Pieterse, 1965; Boer, 1980, 1981). Then, studying incompatibilities at a global level, or at least between what seems to be different strains at a continental or country level, is a challenge.

Keh (1952) was first to address this question by crossing RF, namely $T$. multisetis and GF, namely $T$. bimaculatus, populations collected in California. He obtained $9 / 23$ crosses giving raise to $\mathrm{F} 2$ females and 2/23 with F3 females and then F4 and F5. By doing so, he demonstrated the ability of crossing between the two strains. Boudreaux (1956), by crossing the two forms didn't obtained more than F1 females and one F2 male which gave rise to his own sterile F2 females. Taylor and Smith (1956) and Dillon (1958) also made crosses between the two forms, at a continental (USA) level as well at a global level. They didn't found any compatibility between RF and GF and obtained only sterile F1 females. Dillon's experiments lack control as he did not made intra-strain continental level crosses between the red forms. Monroe (1963) also performed transatlantic crossing and obtained viable F2 females between RF, $T$. telarius (=RF) from Maryland and GF, T. urticae from England. Dosse (1963) with Boudreaux', British, Dutch and German strains obtained fertile F1 hybrids and have continued until the seventh generation.

In England Hussey and Parr (1958) and Parr and Hussey (1960) performed crosses between local RF and GF and obtained low but significant fertile hybrids. Despite these fertile hybrids, they concluded to the presence of two distinct species, but with a hybrid origin of the RF stock rearing! The Dutch school also developed crossing studies (cf. beginning of this section) which sometimes involved the two colour forms. Van de Bund and Helle (1960) did not observed viable F2 females between RF and GF both from the Netherlands, but also 8/36 GF x GF crossings without viable $\mathrm{F} 2$, thereby strengthening the idea of two distinct species.

Dupont (1979) hoping to close the chapter, demonstrated that RF non-diapausing population from New-Caledonia, RF diapausing population from Northern Italy, and the laboratory strain "white eye" obtained from a Dutch green form were all, in varying extents, compatible.
Crosses have been carried out all around the World. With South-African RF and GF strains (namely T. cinnabarinus and T. urticae), Jordaan (1977) obtained fertile hybrids but concluded to separate species due to the F1 females' decline in fertility. With Chinese strains Kuang and Cheng (1990) observed complete isolation. Using the autocidal control concept, Smith (1975) studied hybridization between RF and GF and obtained only sterile F1 females. More recently Attwa et al. (2011) crossed RF and GF (T. cucurbitacearum and T. urticae) from Egypt obtaining viable offspring and concluding to the synonymy between the two species.

At the end of the twentieth century, the Japanese school studied a combination of factors including diapause and colour strain. Gotoh et al. (1993) concluded to a partial compatibility between RF from tomatoes and GF from cucumber, both collected in the Netherlands. Gotoh and Tokioka (1996) crossed non-diapausing RF (NDR), diapausing RF and diapausing GF, all from Japan and observed only partial compatibility between non-diapausing RF and GF, none between diapausing RF and the GF nor the non-diapausing RF. They concluded "Thus, it seems that NDR and GF are conspecific although they show severe genetic incompatibilities". Based on morphological characters, the diapausing RF was later attributed to a new species, Tetranychus pueraricola (Ehara and Gotoh, 1996) and confirmed by molecular analysis (Gotoh et al., 1998; Matsuda et al., 2013). We will see in the diapause paragraph that some clinal variations along a latitude gradient characterises diapause ability. The latest researches were conducted by Sugasawa et al. (2002) also concluded to a strong genetic differentiation between the two conspecific forms, defined by a restricted but present gene flow.

\section{New data}

We have performed population crosses between RF and GF (Table 6). We obtained respectively 110 and 87 F1 females when crossing RF Banyoles (Spain) females and GF London (Canada) males, and reciprocally. By sibmating a continuous offspring was perpetuated until we stopped after 10 generations. Colour results have been presented in colour section. 
TABLE 6: Cross-breeding results between Green and Red forms of Tetranychus urticae from different locations. Numbers of F1 females and males, F2 and F3.

\begin{tabular}{ccccc}
\hline & & & $\begin{array}{c}\text { (F1 Females } \\
\text { Brothers) }\end{array}$ & $\begin{array}{c}\text { (F2 Females } x \\
\text { Brothers) }\end{array}$ \\
\cline { 3 - 5 } Crosses (Female x Male) & F1 females & F1 males & F2 females \& males & F3 females \& males \\
\hline GF-Scotland x RF-Spain & 27 & 102 & 0 & - \\
RF-Spain x GF-Scotland & 97 & 36 & 0 & - \\
GF-Scotland x RF-France & 53 & 81 & 0 & - \\
RF-France x GF-Scotland & 36 & 18 & 0 & - \\
GF-Canada x RF-spain & 87 & 18 & 50 & $1000<$ \\
RF-Spain x GF-Canada & 110 & 49 & $20<$ & - \\
GF-Canada x RF-France & 75 & 17 & 0 & - \\
RF-France x GF-Canada & 98 & 18 & 0 & - \\
\hline
\end{tabular}

GF London strain is the sequenced strain (Grbic et al., 2011) and has been recognized to be T. urticae. It does not bear extra setae as the T. cinnabarinus green sensu Zhang and Jacobson (2000). We have obtained a true compatible cross between RF and GF, strongly supporting, in accordance with the literature, the conspecific status of the green and red forms.

\section{Diapause}

A significant amount of literature support a distribution of the GF in cold temperate latitudes whereas the RF is reported to occur in warmer temperate and subtropical zones, or in greenhouses in Northern geographical areas (e.g. Pritchard and Baker, 1952; Pritchard and Baker, 1955; Boudreaux, 1956; Van de Bund and Helle, 1960; Helle and Van de Bund, 1962; Boudreaux and Dosse, 1963a; Dupont, 1979; De Boer, 1985). In the field, however, it has been observed that the GF and the RF have different habits of hibernation despite a colour-change of the body, which takes place in autumn in the two colour forms (Van de Bund and Helle, 1960). These results let the authors to question a real diapause ability of the RF because hibernating females of this form were able to start their activities a few days after being under favourable conditions with their red colour quickly being restored. They concluded that the RF was not able to enter into diapause and the diapausing form of the
GF was far more resistant to cold than hibernating females of the RF, classifying RF as a homodynamic species. It must be noticed however, that the ability of populations of the RF to enter into diapause may vary with altitude (Dosse, 1966). In Lebanon, in winter, diapausing females of the RF are found on $1500 \mathrm{~m}$ a.s.l. mountains but, on lower altitudes (1000 $\mathrm{m}$ a.s.1.), orange coloured females are mixed with some brown red females laying eggs and bearing dorsal integumental striae smooth or with dorsal lobes. At lower altitudes, the RF develops all the year and no diapause occurs (Dosse, 1966).

In order to verify the capacity to enter in diapause, the criterion sometimes used to consider the two colour forms as distinct species, several attempts have been made to induce diapause in the two colour forms of T. urticae. By exposing juveniles to a short-day photoperiod and a temperature of about $14^{\circ} \mathrm{C}$, winter-type females of two populations of the RF (including the polychaete form) were obtained (Boudreaux, 1956). These females were bright orange, they did not feed, did not lay eggs and they bear smooth dorsal striae. Interestingly, in this work among others, these specimens were not regarded as diapausing (Boudreaux, 1958a; Boudreaux and Dosse, 1963a). Several other experiments failed in inducing diapause in several populations of the RF (Hussey and Parr, 1958; Van de Bund and Helle, 1960; Hazan et al., 1971), or mentioned diapausing forms in the GF but not in the 
RF (Dillon, 1958). By contrast, diapausing females were obtained in a population of the RF from Italy (Helle and Overmeer, 1973; Dupont, 1979), which let Dupont (1979) to conclude that the argument of adaptation to hibernation for species separation was questionable. Additional results confirmed the possibility of the RF to diapause, by showing the successful induction of a facultative imaginal diapause (females turned orange-red in colour, feeding and oviposition stopped) in a Greek population under a short day photoperiod at a temperature of 19 ${ }^{\circ} \mathrm{C}$ (Vaz Nunes, 1986). This work also underlined the fact that the photoperiodic induction response curve obtained with this population of the RF had a great resemblance with the response curves obtained with populations of the GF despite differences in the critical daylight.

The field data on the RF reported by Dosse (1966) can be compared to those obtained on the incidence of diapause among Japanese populations of the GF observed in a latitudinal cline in Japan (Gotoh and Shinkaji, 1981; Takafuji et al., 1991) and also to the induction of diapause in the GF which might vary with the geographical origin of the mite (Bondarenko and Kuan, 1958; Rambier, 1965). In addition, the various unsuccessful attempts to induce diapause in several populations of the RF previously mentioned do not mean a lack of diapause capacity. Indeed, many species of arthropods have populations living in temperate zones which express diapause, while those in the tropics do not (Danks, 1987). It is known that variation in diapause response is maintained by adaptation to local environments (Takafuji et al., 1991; So and Takafuji, 1992), leading to a geographic variation of the diapause potential of populations (Dupont, 1979; Vaz Nunes, 1986). As a consequence, as the ability for diapause can be lost by tetranychid mites populations (Veerman, 1985), diapause ability is not a reliable biological trait to separate GF and RF of T. urticae as two separate taxa.

\section{Host plants specialisation}

Differences in host plant range have sometimes been used as an argument in favour of the separation of the two forms of T. urticae. This is par- ticularly illustrated by the elevation to the rank of sub species of a population of the red tetranychid mite named T. urticae forma dianthica (Dosse, 1952). This mite, later considered a synonym of RF (see "Lobes on dorsal striation" section), leaves on carnation (Dianthus caryophyllus L.) and was usually called the "greenhouse carnation spider mite". Several studies also reported that the RF was usually associated with carnation (Hussey and Parr, 1958; Van de Bund and Helle, 1960; Gotoh and Tokioka, 1996), whereas populations of the GF were unable to develop on this plant (Gotoh and Tokioka, 1996; Van de Bund and Helle, 1960). This difference in the host plants range gave an additional reason to consider the RF as a distinct species from the GF (Van de Bund and Helle, 1960).

However, several examples of populations of the GF living on carnations were progressively also reported (e. g. Taylor and Smith, 1956; Baker and Pritchard, 1960; Parr and Hussey, 1960; Boer, 1985; Takafuji et al., 1991; Takafuji, 1998; Gotoh et al., 2007) which confirms that the colonisation of carnation is not restricted to the RF. A recent study have demonstrated that the colonisation ability of this plant by the GF and the RF may vary with the cultivar (Seki and Toyoshima, 2008). This observation could explain the previous results on the ability of the GF to develop or not on carnations. The capacity of the RF to exploit carnations might rather reveal an adaptation to this host plant than resulted from a speciation event. In agreement with this, feeding preferences were reported to occur among the two forms of T. urticae (Gotoh et al., 1993), supporting the existence of races particularly well adapted to a host plant (Boer, 1985; Navajas, 1998).

All together, results do not support a specific ability of the RF to grow on carnation as an argument to support the separation of the two forms, but rather show that the two forms of T. urticae reflect the diversity of the species with populations that might be more or less adapted to different host plants (Gotoh et al., 1993; Magalhães et al., 2007), but with no clear link between mite colour and a determined host plant or even a host plant range (Navajas, 1998). 


\section{Molecular data as a tool to delimitate taxa}

The development of molecular methods to study systematics of Acari improved considerably over the last 20 years (Navajas and Fenton, 2000) and is provided with new tools to re-examine the status of the red and green forms of T. urticae and to address the controversy about the validity of $T$. cinnabarinus. Based in the genetic variation that can be revealed by DNA sequences, the approach gives estimates of gene exchange among individuals as an indicator of the reproductive success expected among individuals belonging to a same species. Conversely, if gene flow does not occur, as it is the case when comparing individuals from two distinct taxa, a signature of divergence in DNA sequence should be detected as an indicator that individuals belong to distinct taxonomic units. DNA based species discrimination methods are mostly based in PCR amplification of targeted genes or fragments of genes which are successively either sequenced or analysed by PCRRFLP. Among the most popular genomic regions, the cytochrome oxidase I (COI) gene of the mitochondrial genome, is one of the most widely used for species discrimination. The COI is nowadays one of the standardized regions of the genome used in the Barcoding initiative.

Using a fragment of the COI gene, the question whether the red and green forms of T. urticae should be considered separate species was first addressed by Navajas et al. (1996) by the comparison of sequences of mite samples originating from several areas worldwide. In the resulting phylogenetic tree, sequences did not cluster according to the mite colour which strongly supported that the two T. urticae forms belong to the same species. The phylogenetic analysis showed a significant genetic diversity of T. urticae that was organized in two well defined phylogenetic lineages. Further studies on DNA sequence analysis, corroborated the presence of two major COI lineages of T. urticae (Hinomoto et al., 2001; Xie et al., 2006a) and that the colour, either green or red, was an inconsistent criterion to separate T. urticae samples (Hinomoto et al., 2001; Xie et al., 2008; Li et al., 2010).

While in a few studies using sequences of a fragment of the COI from red and green mites col- lected in China, T. cinnabarinus was regarded as a valid species ( $\mathrm{Li}$ et al., 2010), the presented phylogenetic tree does not support monophyly of these sequences. The called $T$ cinnabarinus sequences are scared in several branches of the tree, e.g. T. turkestani (Ugarov and Nikolskii, 1937), T. truncatus Ehara, 1956 and T. urticae, strongly suggesting a misidentification of mites. Hinomoto (2007) firstly reports misidentification of COI sequences in Genbank databases which considered to likely be $T$. truncatus. A recent study re-examined sequences of the most studied fragment (450 nucleotides length) the COI deposited in Genebank and labelled as T. cinnabarinus, together with sequences of T. urticae and closely related species (de Mendonça et al., 2011). All the sequences matched $100 \%$ with at least one T. urticae Genbank entry, often to several entries at $100 \%-99 \%$, and in some cases they matched with related species, T. truncatus or T. kanzawai Kishida, 1927. This work highlights the caveat of inaccuracy of species identification attached to the DNA sequences deposited in databases and in particular the confusing identification of $T$. cinnabarinus.

In conclusion, the question whether the red form of $T$. urticae should be considered as a separate species (T. cinnabarinus) has been addressed by several molecular studies. Phylogenetic analyses of DNA sequences of the red and green mites of $T$. urticae do not support two distinct monophyletic groups according to the colour. Results congruently support that the two colour forms belong to a single taxon.

\section{CONCLUSION}

Literature review on the validity of the two taxa T. urticae and T. cinnabarinus, together with new evidence provided by new data produced for this study, let us to conclude about their synonymy and the validity of the single taxon T. urticae. Several facts support this conclusion. First, both intra and inter-population variation occur for some of the morphological characters having been used to separate the two colour forms and overlap with no clear-cuts. The example of the key character usually used in the genus Tetranychus to distinguish between species, the shape of the aedeagus, illustrates 
particularly this problem. Second, no consistent link between body colour and some characters previously used to separate the two forms (e.g. aedeagus and dorsal lobe shapes) is found. Third, several genetic studies showed that gene flow occurs between the two forms. First reported by Dupont (1979), recent work (e.g. Gotoh and Tokioka, 1996) and the new data here presented confirm that the red and green forms do interbreed and can produce viable progeny. Finally, phylogenetic studies based on molecular data failed in separating GF and RF. All together, numerous studies here discussed converge and give clear evidence to validate the conspecific status of the red and green forms and allows concluding that $T$. cinnabarinus should be considered as a synonym of $T$. urticae.

\section{ACKNOWLEDGEMENTS}

We would like to thank the colleagues who helped us by providing missing useful papers. These are Morten Brendstrup-Hansen, Carlos Flechtmann, Thierry Hance, Mohammad Hassan Shamsi and Zhi-Qiang Zhang. This work was partially funded by European Union Research Executive Agency Foundation FP7 IRSES Grant Number 269133 project.

\section{REFERENCES}

Altincicek B., Kovacs J.L., Gerardo N.M. 2012 — Horizontally transferred fungal carotenoid genes in the twospotted spider mite Tetranychus urticae - Biology Letters, 8: 253-257. doi:10.1098/rsbl.2011.0704

Attwa W.A., El-Laithy A.Y.M., EL-Saiedy E.M., AbdElrahaman S.E., Sadek H.E.S. 2011 - Cross breeding between the two spider mites Tetranychus urticae Koch and Tetranychus cucurbitacearum (Sayed) in Egypt Acarines, 5: 47-49.

Baker E.W., Pritchard A.E. 1960 - The tetranychoid mites of Africa - Hilgardia, 29: 455-574.

Baker E.W., Tuttle D.M. 1994 - A guide to the spider mites (Tetranychidae) of the United States - West Bloomfield, USA: Indira Publishing House. pp. 347.

Blauvelt W.E. 1945 - The internal morphology of the common red spider mite (Tetranychus telarius Linn.) Cornell University Agricultural Experiment Station, Memoir 270: 1-35.
Boer R. de 1980 - Genetic affinities between spider mite Tetranychus urticae (Acarina: Tetranychidae) populations in a non-agricultural area - Entomol. Exp. Appl., 28: 22-28. doi:10.1111/j.15707458.1980.tb02983.x

Boer R. de 1981 - Genetic affinities between spider mite Tetranychus urticae populations in a non-agricultural area. II - Entomol. Exp. Appl., 30: 63-67. doi:10.1111/j.1570-7458.1981.tb03585.x

Boer R. de 1985 - Reproductive barriers — In: Helle W., Sabelis M.W., (Eds). Spider mites: their biology, natural enemies and control. Amsterdam: Elsevier Science Publishers B. V. p. 193-200.

Boisduval A. 1867 - Essai sur l'entomologie horticole Paris, France. pp. 648.

Bolland H.R., Gutierrez J., Flechtmann C.H.W. 1998 World catalogue of the spider mite family (Acari: Tetranychidae) — Leiden: Brill Academic Publishers. pp. 392.

Bondarenko N.V., Kuan K.Y. 1958 - Peculiarities in the origin of diapause in different geographical populations of the spider mite - Dokladi Akademii Nauk SSSR, 119: 1247-1250.

Boudreaux H.B. 1956 - Revision of the two-spotted spider mite (Acarina, Tetranychidae) complex, Tetranychus telarius (Linnaeus) - Ann. Entomol. Soc. Am., 49: 43-48.

Boudreaux H.B. 1958a - The effect of relative humidity on egg-laying, hatching, and survival in various spide mites - J. Insect Physiol., 2: 65-72. doi:10.1016/00221910(58)90029-5

Boudreaux H.B. 1958b - Tetranychus tumidus Banks versus Tetranychus gloveri Banks (Acarina, Tetranychidae) — Ann. Entomol. Soc. Am., 51: 174-177.

Boudreaux H.B. 1959 - A viruslike transovarian factor affecting morphology in spider mites - J. Insect Pathol., 1: 270-280.

Boudreaux H.B. 1963 - Biological aspect of some phytophagous mites - Annu. Rev. Entomol., 8: 137-154. doi:10.1146/annurev.en.08.010163.001033

Boudreaux H.B., Dosse G. 1963a - Concerning the names of some common spider mites - Advances in Acarology. Ithaca, Usa: Comstock Publishing Associates. p. 350-364.

Boudreaux H.B., Dosse G. 1963b - The usefulness of the taxonomic characters in females of the genus Tetranychus Dufour (Acari : Tetranychidae) - Acarologia, 5: 13-33.

Brandenburg R.L., Kennedy G.G. 1981 — Differences in dorsal integumentary lobe densities between Tetranychus urticae Koch and Tetranychus cinnabarinus (Boisduval) (Acarina: Tetranychidae) from northeastern 
North Carolina - Int. J. Acarol., 7: 231-234. doi:10.1080/01647958108683266

Carbonnelle S., Hance T. 2004 - Cuticular lobes in the Tetranychus urticae complex (Acari: Tetranychidae): A reliable taxonomic character? - Belg. J. Zool., 134: 51-54.

Danks H.V. 1987 — Insect Dormancy: an ecological perspective - Ottawa: Biological Survey of Canada (Terrestrial Arthropods). pp. 439.

Davis D.W. 1952 - Biological studies on three forms of the two-spotted spider mite - Pan Pacific Entomologist, 28: 1-6.

de Mendonça R., Navia D., Diniz I., Auger P., Navajas M. 2011 - A critical review on some closely related species of Tetranychus sensu stricto (Acari: Tetranychidae) in the public DNA sequences databases - Experimental and Applied Acarology: 1-23. doi:10.1007/s10493-011-9453-5

Dieleman J., Overmeer W.P.J. 1972 — Preferential mating hampering the possibility to apply a genetic control method against a Population of Tetranychus urticae Koch — Zeit. Angew. Entomol., 71: 156-161.

Dillon L.S. 1958 - Reproduction isolation among certain spider mites of the Tetranychus telarius complex, with preliminary notes - Ann. Entomol. Soc. Am., 51: 441-448.

Dosse G. 1952 - The greenhouse spider mite, Tetranychus urticae Koch forma dianthica and its control Pflanzenschutz-Nachrichten Bayer, 5: 239-267.

Dosse G. 1963 - The course of an experimental crossing between Tetranychus dianthica Dosse and T. telarius Koch (= cinnabarinus Boisduval) - Mitt. Schweiz. Entomol. Ges., 36: 49-52.

Dosse G. 1964 - Beobachtungen über Entwicklungstendenzen im Tetranychus urticae-cinnabarinus Komplex (Acari, Tetranychidae) - Pflanzenschutzberichte, 31: 113-128.

Dosse G. 1966 — Beiträge zum diapause -Problem von Tetranychus urticae Koch und Tetranychus cinnabarinus Boisduval-Komlex im Libanon (Acarina, Tetranychidae) - Pflanzenschutzberichte, 34: 129-138.

Dosse G., Boudreaux H.B. 1963 - Some problems in spider mite taxonomy involving genetics and morphology - Advances in Acarology. Ithaca, New-York: Comstock Publishing Associates. p. 343-349.

Dosse G., Langenscheidt M. 1964 - Morphologische, biologische und histologische Untersuchungen an Hybriden aus dem Tetranychus urticae-cinnabarinus Komplex (Acari, Tetranychidae) - Zeitschrift fur Angewandte Entomologie, 54: 349-359. doi:10.1111/j.14390418.1964.tb02950.x
Dosse G., Musa S. 1967 - Phytophagous mites in Lebanon and their predators - Magon, Institut de Recherches Agronomiques, Liban, 12: 1-23.

Dupont L.M. 1979 - On gene flow between Tetranychus urticae Koch, 1836 and Tetranychus cinnabarinus (Boisduval) Boudreaux, 1956 (Acari: Tetranychidae): synonymy between the two species - Entomol. Exp. Appl., 25: 297-303. doi:10.1111/j.15707458.1979.tb02882.x

Ehara S. 1999 - Revision of the spider mite family Tetranychidae of Japan (Acari, Prostigmata) — Species Diversity, 4: 63-141.

Ehara S., Gotoh T. 1996 - Two new species of spider mites occurring in Japan (Acari, Tetranychidae) - J. Acarol. Soc. Jpn., 5: 17-25. doi:10.2300/acari.5.17

Ewing H.E. 1913 - The taxonomic value of characters of the male genital armature in the genus Tetranychus Dufour - Ann. Entomol. Soc. Am., 6: 453-460.

Ewing H.E. 1914 - The common red spider or spider mite - Oregon Agricultural College Experimental Station Bulletin, 121: 1-95.

Gasser R. 1951 - Zur Kenntnis der gemeinen Spinnmilbe Tetranychus urticae Koch - Mitt. Schweiz. Entomol. Ges., 24: 217-262.

Geest L.P.S.v.d. 1985 - Aspects of physiology — In: Helle W., Sabelis M.W., (Eds). Spider mites: their biology, natural enemies and control. Amsterdam: Elsevier Science Publishers B. V. p. 171-182.

Goka K., Takafuji A. 1990 - Genetical studies on the diapause of the two-spotted spider mite, Tetranychus urticae (Koch) - Appl. Entomol. Zool., 25: 119-125.

Gotoh T. 1986 - Termination pattern of diapause in the two-spotted spider mite, Tetranychus urticae Koch (Acarina: Tetranychidae) in Sapporo - Appl. Entomol. Zool., 21: 480-481.

Gotoh T., Bruin J., Sabelis M.W., Menken S.B.J. 1993 - Host race formation in Tetranychus urticae: genetic differentiation, host plant preference, and mate choice in a tomato and a cucumber strain - Entomol. Exp. Appl., 68: 171-178. doi:10.1111/j.15707458.1993.tb01700.x

Gotoh T., Gutierrez J., Navajas M. 1998 - Molecular comparison of the sibling species Tetranychus pueraricola Ehara \& Gotoh and T. urticae Koch (Acari: Tetranychidae) - Entomol. Sci., 1: 55-57.

Gotoh T., Shinkaji N. 1981 - Critical photoperiod and geographical variation of diapause induction in the twospotted spider mite, Tetranychus urticae Koch (Acarina: Tetranychidae) in Japan - Jpn. J. Appl. Entomol. Zool., 25: 113-118. doi:10.1303/jjaez.25.113

Gotoh T., Sugasawa J., Noda H., Kitashima Y. 2007 - Wolbachia-induced cytoplasmic incompatibility in 
Japanese populations of Tetranychus urticae (Acari: Tetranychidae) - Exp. Appl. Acarol., 41: 1-16. doi:10.1007/s10493-007-9072-3

Gotoh T., Tokioka T. 1996 - Genetic compatibility among diapausing red, non-diapausing red and diapausing green forms of the two-spotted spider mite, Tetranychus urticae Koch (Acari: Tetranychidae) - Jpn. J. Entomol., 64: 215-225.

Grbic M., Van Leeuwen T., Clark R.M., Rombauts S., Rouze P., Grbic V., Osborne E.J., Dermauw W., Phuong Cao Thi N., Ortego F. et al. . 2011 - The genome of Tetranychus urticae reveals herbivorous pest adaptations - Nature, 479: 487-492.

Hance T., Neuberg P., Noel-Lastelle C. 1998 - The use of fecundity, lobe biometry and the RAPD-PCR technique in order to compare strains of Tetranychus sp - Exp. Appl. Acarol., 22: 649-666. doi:10.1023/A:1006010822267

Harvey F.L. 1892 - The two-spoted mite - Annual Report Maine Agricultural Experimental Station: 133144.

Hatzinikolis E.N. 1970 - Contribution à l'étude de l'espèce Tetranychus telarius (Linnaeus, 1758) (complex) (Acarina: Tetranychidae) - Ann. Inst. Phytopathol. Benaki, 9: 207-218.

Hazan A., Tahori A.S., Gerson U. 1971 — Failures to induce diapause in an acaricide-susceptible strain of the carmine spider mite — Isr. J. Entomol., 6: 97-105.

Helle W. 1967 - Fertilization of the two-spotted spider mite (Tetranychus urticae: Acari) - Entomol. Exp. Appl., 10: 103-110. doi:10.1111/j.15707458.1967.tb00049.x

Helle W., Overmeer W.P.J. 1973 - Variability in Tetranychid mites - Annu. Rev. Entomol., 18: 97-120. doi:10.1146/annurev.en.18.010173.000525

Helle W., Pieterse A.H. 1965 - Genetic affinities between adjacent populations of spider mites (Tetranychus urticae Koch) - Entomol. Exp. Appl., 8: 305-308. doi:10.1111/j.1570-7458.1965.tb00866.x

Helle W., Van de Bund C.F. 1962 - Crossbreeding experiments with some species of the Tetranychus urticae group - Entomol. Exp. Appl., 5: 159-165. doi:10.1111/j.1570-7458.1962.tb00578.x

Hinomoto N., Dinh Pha T., Anh Tuan P., Thi Bao Ngoc L., Tajima R., Ohashi K., Osakabe M., Takafuji A. 2007 - Identification of spider mites (Acari: Tetranychidae) by DNA sequences: a case study in northern Vietnam - Int. J. Acarol., 33: 53-60. doi:10.1080/01647950708684501

Hinomoto N., Osakabe M., Gotoh T., Takafuji A. 2001 - Phylogenetic analysis of green and red forms of the two-spotted spider mite, Tetranychus urticae Koch
(Acari: Tetranychidae), in Japan, based on mitochondrial cytochrome oxidase subunit I sequences - Appl. Entomol. Zool., 36: 459-464. doi:10.1303/aez.2001.459

Hussey N.W., Parr W.J. 1958 - A genetic study of the colour forms found in populations of the greenhouse red spider mite, Tetranychus urticae Koch Ann. Appl. Biol., 46: 216-220. doi:10.1111/j.17447348.1958.tb02199.x

Hussey N.W., Parr W.J. 1963 - Dispersal of the glasshouse red spider mite Tetranychus urticae Koch (Acarina, Tetranychidae) - Entomol. Exp. Appl., 6: 207-214. doi:10.1111/j.1570-7458.1963.tb00619.x

Jeppson L.R., Keifer H.H., Baker E.W. 1975 - Mites injurious to economic plants - Berkeley: University of California Press. pp. xxiv +614 .

Jordaan L.C. 1977 - Hybridization studies on the Tetranychus cinnabarinus complex in South Africa (Acari: Tetranychidae) - J. Entomol. Soc. South. Afr., 40: 147-156.

Keh B. 1952 - Mating experiments with the two-spotted spider mite complex. - J. Econ. Entomol., 45: 308-311.

Kuang H.Y., Cheng L.S. 1990 - Studies on the differentiation of two sibling species, Tetranychus cinnabarinus (Boisduval) and T. urticae Koch - Acta Entomol. Sin., 33: 109-116.

Li G.Q., Xue X.F., Zhang K.J., Hong X.Y. 2010 — Identification and molecular phylogeny of agriculturally important spider mites (Acari: Tetranychidae) based on mitochondrial and nuclear ribosomal DNA sequences, with an emphasis on Tetranychus - Zootaxa: 1-15.

Li T., Chen X.L., Hong X.Y. 2009 - Population genetic structure of Tetranychus urticae and its sibling species Tetranychus cinnabaribus (Acari: Tetranychidae) in China as inferred from microsatellite data. - Ann. Entomol. Soc. Am., 102: 674-683. doi:10.1603/008.102.0412

Magalhães S., Forbes M., Skoracka A., Osakabe M., Chevillon C., McCoy K. 2007 - Host race formation in the Acari - Exp. Appl. Acarol., 42: 225-238. doi:10.1007/s10493-007-9091-0

Matsuda T., Fukumoto C., Hinomoto N., Gotoh T. 2013 DNA-Based Identification of spider mites: Molecular evidence for cryptic species of the genus Tetranychus (Acari: Tetranychidae) - J. Econ. Entomol., 106: 463472. doi:10.1603/EC12328

McGregor E.A. 1950 - Mites of the family Tetranychidae — Am. Midl. Nat., 44: 257-420. doi:10.2307/2421963

Metcalf R.L., Newell I.M. 1962 - Investigation of the biochromes of mites - Ann. Entomol. Soc. Am., 55: 350-353.

Meyer M.K.P.S. 1974 - A revision of the Tetranychidae of Africa (Acari) with a key to the genera of the world 
- Entomology Memoir, Department of Agricultural Technical Services, Republic of South Africa: 1-291.

Meyer M.K.P.S. 1987 - African Tetranychidae (Acari: Prostigmata) - with reference to the world genera Entomology Memoir, Department of Agriculture and Water Supply, Republic of South Africa, 69: 1-175.

Migeon A., Dorkeld F. - Spider Mites Web: a comprehensive database for the Tetranychidae [Internet] — [accessed 18 April 2013]. Available from: http:/ / www1.montpellier.inra.fr/CBGP/spmweb /

Mollet J.A., Sevacherian V. 1984 - Effect of temperature and humidity on dorsal strial lobe densities in Tetranychus (Acari: Tetranychidae) - Int. J. Acarol., 10: 159161. doi:10.1080/01647958408683370

Monroe R.S. 1963 - A genetic study of the Tetranychus telarius complex - Acarologia, 5: 545-555.

Murray A. 1877 - Economic Entomology, Aptera - London: Chapman and Hall. pp. 433.

Navajas M. 1998 - Host plant associations in the spider mite Tetranychus urticae (Acari: Tetranychidae): insights from molecular phylogeography - Exp. Appl. Acarol., 22: 201-214. doi:10.1023/A:1006062214318

Navajas M., Fenton B. 2000 - The application of molecular markers in the study of diversity in acarology: a review - Exp. Appl. Acarol., 24: 751-774. doi:10.1023/A:1006497906793

Navajas M., Fournier D., Lagnel J., Gutierrez J., Boursot P. 1996 - Mitochondrial COI sequences in mites: evidence for variations in base composition - Insect Mol. Biol., 5: 281-285. doi:10.1111/j.13652583.1996.tb00102.x

Parr W.J., Hussey N.W. 1960 - Further studies on the reproductive isolation of geographical strains in the Tetranychus telarius complex - Entomol. Exp. Appl., 3: 137-141. doi:10.1111/j.1570-7458.1960.tb02120.x

Parr W.J., Hussey N.W. 1966 - Diapause in the glasshouse red spider mite (Tetranychus urticae Koch): a synthesis of present knowledge - Hort. Res., 6: 121.

Perrot-Minnot M.J., Cheval B., Migeon A., Navajas M. 2002 - Contrasting effects of Wolbachia on cytoplasmic incompatibility and fecundity in the haplodiploid mite Tetranychus urticae - J. Evol. Biol., 15: 808-817. doi:10.1046/j.1420-9101.2002.00446.x

Pritchard A.E., Baker E.W. 1952 - A guide to the spider mites of deciduous fruit trees - Hilgardia, 21: 253287.

Pritchard A.E., Baker E.W. 1955 - A revision of the spider mite family Tetranychidae - San Francisco: Pacific Coast Entomological Society. pp. 472.

Rambier A. 1965 - Etude de quelques populations de Tetranychus urticae Koch - Boll. Zool. Agrar. Bachic., 7: 51-59.
Ros V.I.D., Breeuwer J.A.J. 2007 - Spider mite (Acari: Tetranychidae) mitochondrial COI phylogeny reviewed: host plant relationships, phylogeography, reproductive parasites and barcoding - Exp. Appl. Acarol., 42: 239-262. doi:10.1007/s10493-007-9092-Z

Saba F. 1975 - Comparative studies of species forming two Tetranychid complexes in Morocco - Ann. Entomol. Soc. Am., 68: 797-800.

Seki K., Toyoshima G. 2008 - Carnation cultivar susceptibility to the green form of two-spotted spider mite Tetranychus urticae Koch (Acari: Tetranychidae). - Appl. Entomol. Zool., 43: 347-350. doi:10.1303/aez.2008.347

Smith F.F., Boswell A.L., Webb R.E. 1969 - Segregation between strains of carmine and green two-spotted spider mites - Proceedings of the International Congress of Acarology, 2nd, Sutton Bonington: 155-159.

Smith J.W. 1975 - Spider mites: population suppression by interspecific hybridization - Environ. Entomol., 4: 588-590.

So P.M., Takafuji A. 1992 - Local variation in diapause characteristics of Tetranychus urticae Koch (Acarina: Tetranychidae) - Oecologia, 90: 270-275.

Sugasawa J., Kitashima Y., Gotoh T. 2002 - Hybrid affinities between the green and the red forms of the twospotted spider mite Tetranychus urticae (Acari: Tetranychidae) under laboratory and semi-natural conditions - Appl. Entomol. Zool., 37: 127-139. doi:10.1303/aez.2002.127

Sun J.T., Lian C., Navajas M., Hong X.Y. 2012 - Microsatellites reveal a strong subdivision of genetic structure in Chinese populations of the mite Tetranychus urticae Koch (Acari: Tetranychidae) - BMC Genet., 13.

Takafuji A. 1998 - The Biology of Spider Mite — Tokyo: Springer-Verlag. pp. 214.

Takafuji A., So P.M., Tsuno N. 1991 - Inter- and intrapopulation variations in diapause attribute of the twospotted spider mite, Tetranychus urticae Koch, in Japan - Researches on Population Ecology, 33: 331-344. doi:10.1007/BF02513558

Taylor E.A., Smith F.F. 1956 - Transmission of resistance between strains of two-spotted mites spider mites J. Econ. Entomol., 49: 858-859.

Tuttle D.M., Baker E.W. 1968 - Spider mites of southwestern United States and a revision of the family Tetranychidae - Tuscon, Usa: The University of Arizona Press. pp. 143.

Van de Bund C.F., Helle W. 1960 - Investigations on the Tetranychus urticae complex in N. W. Europe (Acari: Tetranychidae) - Entomol. Exp. Appl., 3: 142-156. doi:10.1111/j.1570-7458.1960.tb02121.x 
Vaz Nunes M. 1986 - Some aspects of induction and termination of diapause in a Greek strain of the mite Tetranychus cinnabarinus (Boisduval) Boudreaux, 1956 (Acari: Tetranychidae) - Exp. Appl. Acarol., 2: 315321. doi:10.1007/BF01193897

Veerman A. 1970 - The pigments of Tetranychus cinnabarinus Boisd. (Acari: Tetranychidae) - Comp. Biochem. Physiol., 36: 749-763. doi:10.1016/0010406X(70)90530-X

Veerman A. 1972 - Carotenoids of wild-type and mutant strains of Tetranychus pacificus McGregor (Acari: Tetranychidae) - Comp. Biochem. Physiol. B: Comp. Biochem., 42: 329-340.

Veerman A. 1974 - Carotenoid metabolism in Tetranychus urticae Koch (Acari:Tetranychidae) - Comp. Biochem. Physiol. B: Comp. Biochem., 47: 101-116.

Veerman A. 1985 - Diapause - In: Helle W., Sabelis M.W., (Eds). Spider mites: their biology, natural enemies and control. Amsterdam: Elsevier Science Publishers B. V. p. 279-310.

Xie L., Hong X.Y., Xue X.F. 2006a - Population genetic structure of the two spotted spider mite (Acari: Tetranychidae) from China - Ann. Entomol. Soc. Am., 99: 959-965. doi:10.1603/00138746(2006)99[959:PGSOTT]2.0.CO;2

Xie L., Miao H., Hong X.Y. 2006b - The two spotted spider mite Tetranychus urticae Koch and the carmine spi- der mite Tetranychus cinnabarinus (Boisduval) in China mixed in their Wolbachia phylogenetic tree - Zootaxa, 1165: 33-46.

Xie L., Xie R.R., Zhang K.J., Hong X.Y. 2008 - Genetic relationship between the carmine spider mite Tetranychus cinnabarinus (Boisduval) and the two-spotted mite T. urticae Koch in China based on the mtDNA COI and rDNA ITS2 sequences - Zootaxa: 18-32.

Zhang Z., Jacobson R.J. 2000 — Using adult female morphological characters for differentiating Tetranychus urticae complex (Acari: Tetranychidae) from greenhouse tomato crops in UK - Syst. Appl. Acarol., 5: 69-76.

Zhang Z.Q. 2003 - Mites of greenhouses: identification, biology and control - . Oxon, UK: CABI Publishing. p. 256. doi:10.1079/9780851995908.0000

\section{COPYRIGHT}

(oc) EY-No-ND Auger P. et al. Acarologia is under free license. This open-access article is distributed under the terms of the Creative Commons-BY-NC-ND which permits unrestricted non-commercial use, distribution, and reproduction in any medium, provided the original author and source are credited. 